IZA DP No. 10004

The Effects of Compulsory Military Service Exemption on Education and Labor Market Outcomes:

Evidence from a Natural Experiment

Huzeyfe Torun

Semih Tumen

June 2016 


\title{
The Effects of Compulsory Military Service Exemption on Education and Labor Market Outcomes: Evidence from a Natural Experiment
}

\author{
Huzeyfe Torun \\ Central Bank of the Republic of Turkey \\ Semih Tumen \\ Central Bank of the Republic of Turkey, \\ ERF and IZA
}
Discussion Paper No. 10004
June 2016

IZA

P.O. Box 7240

53072 Bonn

Germany

Phone: +49-228-3894-0

Fax: +49-228-3894-180

E-mail: iza@iza.org

\begin{abstract}
Any opinions expressed here are those of the author(s) and not those of IZA. Research published in this series may include views on policy, but the institute itself takes no institutional policy positions. The IZA research network is committed to the IZA Guiding Principles of Research Integrity.

The Institute for the Study of Labor (IZA) in Bonn is a local and virtual international research center and a place of communication between science, politics and business. IZA is an independent nonprofit organization supported by Deutsche Post Foundation. The center is associated with the University of Bonn and offers a stimulating research environment through its international network, workshops and conferences, data service, project support, research visits and doctoral program. IZA engages in (i) original and internationally competitive research in all fields of labor economics, (ii) development of policy concepts, and (iii) dissemination of research results and concepts to the interested public.
\end{abstract}

IZA Discussion Papers often represent preliminary work and are circulated to encourage discussion. Citation of such a paper should account for its provisional character. A revised version may be available directly from the author. 


\section{ABSTRACT \\ The Effects of Compulsory Military Service Exemption on Education and Labor Market Outcomes: Evidence from a Natural Experiment ${ }^{\star}$}

Based on a law enacted in November 1999, males born on or before December $31^{\text {st }} 1972$ are given the option to benefit from a paid exemption from compulsory military service in Turkey. Exploiting this natural experiment, we devise an empirical strategy to estimate the intentionto-treat effect of this paid exemption on education and labor market outcomes of the individuals in the target group. We find that the paid exemption reform reduces the years of schooling among males who are eligible to benefit from the reform relative to the ineligible males. In particular, the probability of receiving a college degree or above falls among the eligible males. The result is robust to alternative estimation strategies. We find no reduction in education when we implement the same exercises with (i) data on females and (ii) placebo reform dates. The interpretation is that the reform has reduced the incentives to continue education for the purpose of deferring military service. We also find suggestive evidence that the paid exemption reform reduces the labor income for males in the target group. The reduction in earnings is likely due to the reduction in education. It should be noted, however, that due to the characteristics of the population on the treatment margin, the external validity of these results should be assessed cautiously.

JEL Classification: $\quad$ C21, I21, I26, J21, J31

Keywords: compulsory military service, draft avoidance, intention to treat, education, earnings

Corresponding author:

Semih Tumen

Research and Monetary Policy Department

Central Bank of the Republic of Turkey

Istiklal Cad. No:10

06100 Ulus, Ankara

Turkey

E-mail: semih.tumen@tcmb.gov.tr

\footnotetext{
* We thank the seminar participants at the Central Bank of the Republic of Turkey, Ozyegin University, and the participants of the European Society for Population Economics Conference in Izmir, Royal Economic Society Conference in Brighton, and the Koc University/EAF Workshop in Istanbul for helpful comments. We are particularly grateful to Daniel Rees (the Editor) and two anonymous referees for very useful suggestions and careful reading. The views expressed here are of our own and do not necessarily reflect those of the Central Bank of the Republic of Turkey. All errors are ours.
} 


\section{Introduction}

There is a reviving interest in understanding the impacts of compulsory military service on education and labor market outcomes. In theory, there are costs and benefits of compulsory military service. It is costly for several reasons including human capital depreciation, foregone labor market experience, and foregone earnings. These costs can get larger as the duration of service increases. It also has potential benefits. It is often argued that military service provides unique opportunities to equip individuals with valuable technical skills and discipline that may lead to increased productivity in civilian life. Besides its effect on labor market outcomes, compulsory military service may indirectly affect educational attainment of individuals. In most countries, military service is delayed for those who are enrolled in higher education. Therefore, individuals may attend higher education to avoid or postpone their required military service. Increased education may, in turn, raise earnings capacity. Overall, the net impact of abolishing compulsory military service on education is likely to be negative, whereas the net impact on labor market outcomes is ambiguous. The empirical evidence is also mixed with some studies suggesting that abolishing compulsory military service can have positive effects on labor market outcomes, while others reporting zero or negative effects.

In this paper, we study the impact of a law - enacted on November 1999-offering the option to benefit from a one-time paid exemption from compulsory military service in Turkey. Males born on or before December 31st 1972 - 27 years old and above at the time of the reform - are the eligible group, while those who were born on or after January 1st 1973 are ineligible. The amount of the required payment is 15,000 Deutschmark (approximately \$8,000)—20,000 Deutschmark (approximately $\$ 10,650$ ) for males above 40 years old. ${ }^{1}$ The timing of the reform is purely exogenous, because the main motivation behind the reform is to partially compensate the deficit resulting from the devastating earthquake took place in Izmit - a province close to Istanbul - on August 1999. Based on this reform, a male born on December 31st 1972 is offered the option to relax his military service constraints in exchange for some cash, while another one born 24 hours later is not offered the same option. The duration of compulsory

\footnotetext{
${ }^{1}$ In Turkey, per capita GDP in 1999 was around 4,000 USD, which means that the required payment was much larger than the per capita national income figures at the time of the reform.
} 
military service, which was 9-18 months at the time of the reform, increases the appeal of the paid exemption option. This natural experiment enables us to empirically assess whether the education and labor market outcomes in the treatment group differ from the outcomes in the control group.

We use the 2004-2013 waves of the Turkish Household Labor Force Survey micro-level data sets in our empirical analysis. We cannot observe details on military service; so, whether the individual has benefited from paid exemption or not is unobserved to the econometrician. Instead, we observe the birth dates of the survey respondents, so that we can clearly distinguish between the eligible males from the ineligible ones. Thus, within a narrowly defined birth-date interval centered around the reform date, there exist males who have deferred their military obligations both on the left- and right-hand sides of the reform date. Part of the males born before the cutoff date have chosen to benefit from the exemption. As a result, comparing the outcomes on both sides of the cutoff date with each other identifies the impact of the reform. Although the treatment and control groups are randomly assigned, not everyone in the treatment group used the option. The quasi-experimental design is set up based on the initial assignment and not on the treatment eventually received. Due to imperfect compliance, our estimates should be interpreted as the "intention-to-treat" effects. In other words, we estimate the overall intention-to-treat effect of the paid exemption reform (which also includes the imperfect compliance margin) rather than the pure causal effect.

We apply three different econometric specifications: direct approach, difference in differences, and triple difference. In all of these exercises, we consistently report that paid exemption significantly reduces the total years of completed education. Our estimates suggest a reduction in the range of $0.15-0.20$ years, on average. We interpret this result as an evidence of decreased incentives to continue education for males in the treatment group relative to those in the control group. We further present evidence that the reduction in the years of completed schooling comes from the decline in the probability of receiving a college degree or above. This implies that continuing higher education is partly seen as a means to defer military service; thus, in the absence of compulsory military service, part of the males would not stay 
enrolled in higher education. We also present suggestive evidence that the labor income also tends to decline within the eligible group. To support this result, we provide IV estimates exploiting the variation in schooling outcomes as a consequence of the exogenous policy shift. Jointly evaluating the results on education and earnings, we conclude that the reduction in earnings is likely due to the reduction in education. To check the robustness of these results, we perform two different empirical exercises. First, we perform the same set of regressions for females. We find no effect both for education and earnings. Second, we set two different placebo treatment dates and perform regressions for males as if the paid exemption reform is implemented on these dates rather than the original treatment date. Again, we report no effect for education and earnings.

We would like to emphasize at this stage that the natural experiment that we analyze targets potentially highly-educated males. Based on the brief description of the reform provided above, those who are 27 years old or older have been given the option to benefit from paid exemption. In this group of males, those who have deferred their military service are likely to be either enrolled in college or in graduate education. In this sense, we analyze the impact of paid exemption on the outcomes of better-educated individuals. Our findings also confirm this view: the paid-exemption reform reduces probability of receiving a college degree or above suggesting that enrolling in college or graduate school partially serves as a means for deferring required military service in Turkey.

The plan of the paper is as follows. Section 2 reviews the literature on compulsory military service and relates/compares our paper to the relevant work in the literature. Section 3 describes the institutional environment in Turkey. Section 4 provides a definition of our data and presents the details of our identification strategy. Section 5 discusses the results. Section 6 frames and interprets the estimates. Section 7 concludes. 


\section{Related Literature}

There is a large literature investigating the impact of compulsory military service on various outcomes. Research on compulsory military service is useful for policy, because there is an ongoing debate about the costs and benefits of replacing the compulsory military service with more flexible alternative systems. From our vantage point, papers in this literature can be grouped under two categories based on their main outcome of interest: $(i)$ studies focusing on wage and employment outcomes and $(i i)$ those focusing on educational outcomes. Papers in the first category estimate the impact of both peacetime and wartime military conscription on civilian wage and employment outcomes. The results, however, are mixed and there is no consensus in the literature about the impact of compulsory military service on wage and employment outcomes. Using the draft lottery for the Vietnam War as a natural experiment, Angrist (1990) shows that veteran status has reduced civilian earnings considerably in the United States. However, subsequent studies find that the earnings gap between veterans and non-veterans has diminished quickly over time [Angrist and Chen (2011), Angrist, Chen, and Song (2011)]. Angrist and Krueger (1994) report that the World War II veterans earn no more than non-veterans. In one of the earliest studies on this topic, Imbens and van der Klaauw (1995) find that conscription in the Netherlands is associated with around a 5 percent loss in annual earnings relative to those who did not serve in the military and this result persists even after correcting for potential channels of selectivity. Bauer, Bender, Paloyo, and Schmidt (2012) show using a regression discontinuity design that compulsory military service has virtually zero effect on labor market outcomes in Germany. A similar result is documented by Grenet, Hart, and Roberts (2011) using British data. Card and Cardoso (2009) find using data from Portugal that peacetime conscription has a positive effect on the labor market outcomes of low-educated males, while its effect on better-educated males is nil.

Papers in the second category investigate the role of compulsory military service in changing the schooling decisions of individuals. Card and Lemieux (2001) find that draft avoidance behavior raised college attendance rates by 4-6 percentage points in the United states in late 1960s. Maurin and Xenogiani (2007) document that the reform abolishing conscription in 
France has reduced time spent in school among males. They argue that conscription provides incentives for males to spend extra time in school, which, in turn, leads to increased earnings potential. Bauer, Bender, Paloyo, and Schmidt (2014) report using a regression discontinuity approach that conscription increased the likelihood of completing higher education in Germany. Di Pietro (2013) shows, on the other hand, that abolishing compulsory military service in Italy did not have any effect on college enrollment rates. $^{2}$

Our paper is most closely related to the papers in the second strand. The closest paper to ours, in terms of the nature of the results, is Maurin and Xenogiani (2007). Similar to their paper, we find that being exempt from the compulsory military service reduces the years of completed education and labor market earnings. We also provide suggestive evidence that the decline in earnings is possibly due to the decline in completed education. Enrollment in higher education is effectively used by some males to defer military service. Part of the males in this group do not continue higher education after being exempt from military service. This finding is also related to Card and Lemieux (2001) in the sense that it specifies college enrollment as a means to defer/avoid military service. Our paper contributes to the literature in two ways. First, it provides additional evidence on the impact of compulsory military service on education and labor market outcomes by using a natural experiment-i.e., a paid-exemption reform - that targets higher-educated individuals. Second, along with Torun (2014), this is one of the first papers attempting to estimate the impact of compulsory military service on education and labor market outcomes in Turkey.

There are several other studies focusing on different aspects of the link between compulsory military service and labor market outcomes. Galiani, Rossi, and Schargrodsky (2011) document that conscription increases the likelihood of developing a crime record. Papers including Bedard and Deschenes (2006), Dobkin and Shabani (2009), and Autor, Duggan, and Lyle (2011) report negative impact of conscription on health outcomes. Torun (2014) shows using cross-country micro data that anticipation of compulsory military service reduces the likeli-

\footnotetext{
${ }^{2}$ Barr (2016) argues that the tradeoff between enlistment versus college enrollment upon high-school graduation is subject to financial constraints that could be relaxed through merit-aid programs. There are also several papers, including De Tray (1982), Angrist (1993), Bound and Turner (2002), Simon, Negrusa, and Warner (2010), and Barr (2015), arguing that various waves of the G.I. Bill may have led to increased educational attainment among veterans.
} 
hood of labor market participation among young individuals.

\section{Institutional Setting}

\subsection{Military Service in Turkey}

This section describes the general institutional features of compulsory military service in Turkey. Compulsory military service system was introduced in the early 20th century in Turkey. Turkey still relies on the compulsory military service system to supplement the professional armed forces with qualified personnel. The system requires all males above 20 years old — with good health, normal BMI values, and no disabilities — to enlist in the military. ${ }^{3}$ Within the year they turn 19, males from a particular birth cohort are called for medical and psychological examinations. Males with temporary health problems are deferred from service. Unlike the case in some other countries, there is no occupation-based exemption, which keeps the number of permanent exemptions at reasonably low levels. For example, police and firemen are not exempt from the military service. Yet there are other forms of exemptions. For example, a male whose brother lost his life during military service or was seriously injured is exempt from compulsory military service. The laws do not allow conscientious objection.

Males that are physically and mentally fit are not necessarily called up immediately. Those who are enrolled in higher education can defer their military service until age 29. High school graduates and those with two-year college degrees can defer their service until the age 22 and 23, respectively. Males with four-year college degree can defer their service up to two years following graduation. The law enacted in November 1999 offers males, who are born in 1972 or before, the option to benefit from a one-time paid exemption from compulsory military service. Thus, 27 year-old or older males, who had not already completed their military service, could benefit from the exemption option. Given the deferment regulations, most males, who had not served until age 27, must be either enrolled in higher education or must be a new college graduate. ${ }^{4}$

\footnotetext{
${ }^{3}$ Females are exempt from compulsory military service in Turkey, but they are allowed to join the army as professional military officers. Males with severe health problems, extreme BMI values, and disabilities are permanently exempted from the military service.

${ }^{4}$ There may also be non-college graduate males, who avoided the service without a legitimate excuse for deferral. These are
} 
The duration of compulsory military service is changed several times in Turkey throughout the 20th century and the maximum duration is reached during the World War II era. Between 1995 and 2003, the duration of service was 18 months. By a law enacted in 2003, the duration of compulsory military service was reduced from 18 to 15 months. The most recent change was made in October 2013, which shortened the duration of service form 15 months to 12 months - effective January 2014. Since we investigate the effect of paid exemption law in 1999, the relevant duration of compulsory military service for our analysis is 18 months.

It should be noted that the duration of military service also depends on higher education status. From 1995 to 2003, males with two-year college degrees and those with lower degrees served for full term, 18 months, as enlisted soldiers. The 18-month military service as an ordinary conscript is a difficult task for most young males. A four-year college graduate serves under more preferable conditions. Those who have four-year college degree either serve full term, 18 months, as an officer candidate among military officers or they serve half term, 9 months, among enlisted soldiers. The final allocation of college graduates between 18-month service and 9-month service depends on both individual preferences and the necessities of the army. Males who studied in certain fields, such as medicine or engineering, are more likely to be assigned 18-month officer candidate service. Unlike other conscripts, college graduates who serve for 18 months receive a monthly salary. ${ }^{5}$ Officer candidates also have the option to live outside the barracks with or without their families. On top of these, they have the privilege of holding a rank in the armed forces. Four-year college graduates, who serve for 9 months among enlisted privates also have advantages. They are not paid, yet they serve for the half term. Moreover, although 9-month serving college graduates are not among officers, they are usually assigned easier tasks that are compatible with their degrees.

There are pecuniary and non-pecuniary returns to education including higher wages, better health, and prestige. For those who are at the margin of attending a four-year college, a more comfortable military service is another incentive in Turkey. Anecdotal evidence shows that,

\footnotetext{
called the draft evaders or dodgers.

${ }^{5}$ In practice, all non-college graduate conscripts also receive extremely small, symbolic salaries. Yet, the salary of the candidate officers is approximately equal to a teacher's salary, around $\$ 1000$.
} 
especially among two-year college graduates, a comfortable military service is an incentive for attending a four-year college. We argue and empirically show that the paid exemption law in 1999 takes away this incentive and reduces the college graduation rate among males born before the cutoff date of birth compared to males born after the cutoff.

All conscripts receive basic training for around two months and, after that, they are allocated to their divisions for active duty. The unit in the military that a male joins and the region where he serves are determined by the military. The majority of males with no college degree are assigned to the Army, and relatively fewer males are assigned to the Air Force and the Navy. Although the exact number of conscripts varies over time, the Turkish armed forces typically comprise of around 200,000 officers and professional soldiers, and 400,000 conscripts.

\subsection{The 1999 Paid Exemption Reform}

Since the establishment of compulsory military service in Turkey, a number of temporary laws have provided the option of paid exemption to those who are far older than the typical conscription age. Each regulation allowed for suitable males to apply for paid exemption within a couple of months after the ratification of the law. The timing of these temporary laws is generally exogenous and there is not a predetermined rule regarding the amount of payment and the cutoff age for eligibility. The recent laws came into force in 1987, 1992, 1999, 2011, and 2014. The cutoff ages were 40 in 1987, 27 in 1992 and 1999, 29 in 2011, and 27 in 2014. The payments were around $\$ 8,000$ in $1999, \$ 16,000$ in 2011 , and $\$ 8,000$ in 2014 . The number of actual participants is relatively low for the 1987 and 1992 laws. The 2011 and 2014 laws are quite new and the available information is not enough to assess the impact of the reform on educational and labor market outcomes of the eligible males. The 1999 is particularly suitable for empirical analysis since $(i)$ the number of males who have actually benefited from the exemption is relatively large and $(i i)$ we have quite rich information regarding the educational and labor market outcomes of the eligible males.

As mentioned above, the timing of the law is exogenous. The 1999 law, the focus of this article, came into force after a devastating earthquake in Izmit in August 1999. The motivation was 
to raise extra revenue necessary for recovery following the earthquake. The paid exemption law came into force in November 1999. The law gave the option to males, who had not yet completed their military service and were not in the army at the time of the reform, to pay 15,000 Deutschmark (approximately \$8,000) and serve for 21 days instead of a full term. ${ }^{6}$ Males who were born on or before December 31st 1972 were given this option. The cutoff birth date corresponded to the age 27 and it was determined in coordination with the armed forces considering the personnel requirements of the army at the time. So, a significant portion of the actual participants were either enrolled in college or new college graduates. The required payment was allowed to be paid in four installments. Since it was a temporary law, eligible males were supposed to apply for the paid exemption in the following six months after the enactment of the law. Those who were already serving in the military at the time the reform was legislated did not have the option to benefit from the exemption.

Although, the law significantly shortened the service time, it did not make it zero. The participants of 1999 paid exemption served for 21 days - during which they received basic military training. Remember that in the absence of the paid exemption law, non-college graduates serve for 18 months and college graduates serve for 9 or 18 months. So a 21-day service is considerably shorter than the normal duration of the military service. For those who benefit from the paid exemption law, more favorable conditions during military service is no more an incentive for receiving a college degree.

\section{Empirical Analysis}

\subsection{Data}

We use the 2004-2013 waves of the Household Labor Force Survey (LFS) conducted by the Turkish Statistical Institute (TurkStat). Each survey covers about 150,000 households and 500,000 individuals annually, and reports their demographic characteristics along with detailed labor market outcomes. The LFS is a micro-level, nationally-representative, and publicly-

\footnotetext{
${ }^{6}$ For males who were above 40 , the payment was 20,000 Deutschmark (approximately $\$ 10,650$ ). Yet, there were very few males who had not served until age 40 .
} 
available data set. It captures the main characteristics of the civilian non-institutional population and it is the main data source for the national labor force and employment statistics for Turkey. In order to distinguish between those who were affected by the law and those who were not, we obtained additional files from TurkStat, which are not publicly available, on the year of birth and month of birth of respondents and merged them with the original data. ${ }^{7}$ Otherwise, the age variable would be a rather inaccurate measure to define eligibility.

The paid exemption law affected those who were born on or before December 31, 1972. We restrict our sample to individuals born around the cutoff date in the survey years from 2004 to 2013. Males who were born in 1972 were at the age of 32 in 2004 and 41 in 2013 . So the sample consists of prime age males and females who already completed their schooling decisions. Table (1) provides the sample statistics for the main variables, separately for males and females for the baseline sample used in this paper.

The age variable in the data shows the completed age of individuals. Around 3.3 percent of our baseline sample is missing year of birth information. We drop those missing year of birth and analyze a sample of 549,972 individuals aged 27-44 from survey years 2004-2013. The variable for real earnings shows the monthly wages and includes overtime work payments and bonuses - the earnings regressions include only the salaried workers. The real earnings are denominated in 2004 Turkish liras. The non-response rate for wage information among salaried workers is quite small, at 4.5 percent. A detailed description of the key variables used in the empirical analysis is provided in the Data Appendix. Figures A1-A4 in the Online Appendix present the density histograms of birth years (men versus women) as well as the continuity of the covariates used in the empirical analysis. ${ }^{8}$

\subsection{Identification Strategy}

The paid exemption reform has a sharp cutoff date: males born on or before 31 December 1972 are eligible and those born after this date are ineligible. The reform date is the end of 1999, while our data set covers the LFS waves from 2004 to 2013. This means that we

\footnotetext{
${ }^{7}$ We would like to thank the staff in the Labor Force Statistics Department of TurkStat.

${ }^{8}$ The Online Appendix can be reached from: http://www.semihtumen.com/Home/research.
} 
have information on the ex post educational and labor market outcomes. We do not observe who have actually benefited from the reform and who have not. We observe the birth dates of the survey respondents as month-year pairs and we are only able to distinguish between the eligible versus ineligible males. Think of a narrowly defined birth-date interval centered around the cutoff date. There exist males who have deferred their military obligations both on the left- and right-hand sides of the cutoff date. Part of the males born before the cutoff date have chosen to benefit from the exemption. In other words, although the treatment and control groups are randomly assigned, not everyone in the treatment group has benefited from the reform. Our quasi-experimental design is based on the initial assignment and not on the treatment eventually received. Our estimates should be interpreted as the "intention-to-treat" (ITT) effects, since there is imperfect compliance within the treatment group.

The ITT estimation is often regarded in the program evaluation literature as a solution to the imperfect compliance problem [Fisher, Dixon, Herson, Frankowski, Hearron, and Peace (1990)]. ITT analysis strictly depends on the randomized treatment assignment and ignores all sorts of non-compliance in the post-protocol period. Because of this feature, it is sometimes described with the phrase "once randomized, always analyzed" [Hennekens, Buring, and Mayrent (1987)]. The ITT effect also tends to be smaller than the true average treatment effect (i.e., it likely underestimates the true causal effect) because of imperfect compliance [Angrist and Pischke (2008)]. Thus, although the ITT can be regarded as a lower-bound estimate of the impact, it is more policy relevant than the average treatment effect parameter in the empirical analysis of voluntary programs [Bloom (2008)].

We try three different empirical specifications each relying on different identifying assumptions: direct approach, difference in differences, and triple difference. Below we describe each of these specifications in detail. Before doing so, we would like to clarify one point. The cutoff date separates those who were born in December from those born in January. It is well-known that education and labor income are correlated with season of birth not only through the potential interactions between season of birth and compulsory schooling laws [see, e.g., Angrist and Krueger (1991)], but also through the fact that children born toward the end of the year are 
much more likely to have wealthier and better-educated parents than children born early in the year [Bound, Jaeger, and Baker (1995), Buckles and Hungerman (2013)]. In a companion paper [Torun and Tumen (2015)], we clearly document the relevance of this concern for micro-level data sets in Turkey. ${ }^{9}$ When this is the case, the cutoff date accidentally captures the family background effects; therefore, it is necessary to implement identification strategies which also take this important point into account. The following empirical strategies are designed having this problem in mind.

Direct approach. Our first specification is given by the following equation:

$$
y_{i, r, t, m, s}=\alpha+\delta \cdot B_{i}+\boldsymbol{\theta}^{\prime} \cdot \boldsymbol{X}_{i}+g(t)+f_{r}+f_{s}+f_{m}+\epsilon_{i, r, t, s, m},
$$

where $i, r, t, m$, and $s$ index individuals, regions, years of birth, months of birth, and survey years, respectively, $y$ is educational attainment, $B$ is a dummy variable taking 1 if the individual is born on or before December 31st 1972 and 0 after December 31st 1972, $\boldsymbol{X}$ is a vector of individual-level characteristics, $g(t)$ is a polynomial defining the time trend variable with respect to the year of birth, $f_{r}$ denotes region fixed effects, $f_{s}$ denotes survey-year fixed effects, $f_{m}$ denotes month-of-birth fixed effects, and $\epsilon$ is an error term. The vector of individual-level characteristics, $\boldsymbol{X}$, includes a full set of age dummies and an urban/rural dummy. Variables such as labor market experience, marital status, and the number of children are not used as regressors, because these variables are "outcomes" and are influenced by the individual's decisions related to the timing of the compulsory military service. Finally, to represent the time trend that could emanate from birth years, we use a cubic specification. Using alternative specifications do not alter the results.

Figure (1) visualizes our empirical design. We focus on four different windows of observation. The shortest one makes a comparison among those who were born in 1972 versus $1973 .{ }^{10}$ The

\footnotetext{
${ }^{9}$ Torun and Tumen (2015) show that around 20 percent of all individuals in Turkey are January-born due to a certain type of misreporting. They find that misreporting the month of birth as January strongly predicts worse socio-economic outcomes. They also argue that caution should be exercised in empirical analyses relying on discontinuities that occur along the December/January divide in terms of month of birth.

${ }^{10}$ Note that the analysis in the small window may not directly give use the impact of the paid exemption reform. The coefficient $\delta$ yields the combined effect of the paid-exemption reform and a simple cohort effect. To overcome this problem, we enlarge the windows and include the year of birth trends to disentangle the effect of the reform from the cohort effects.
} 


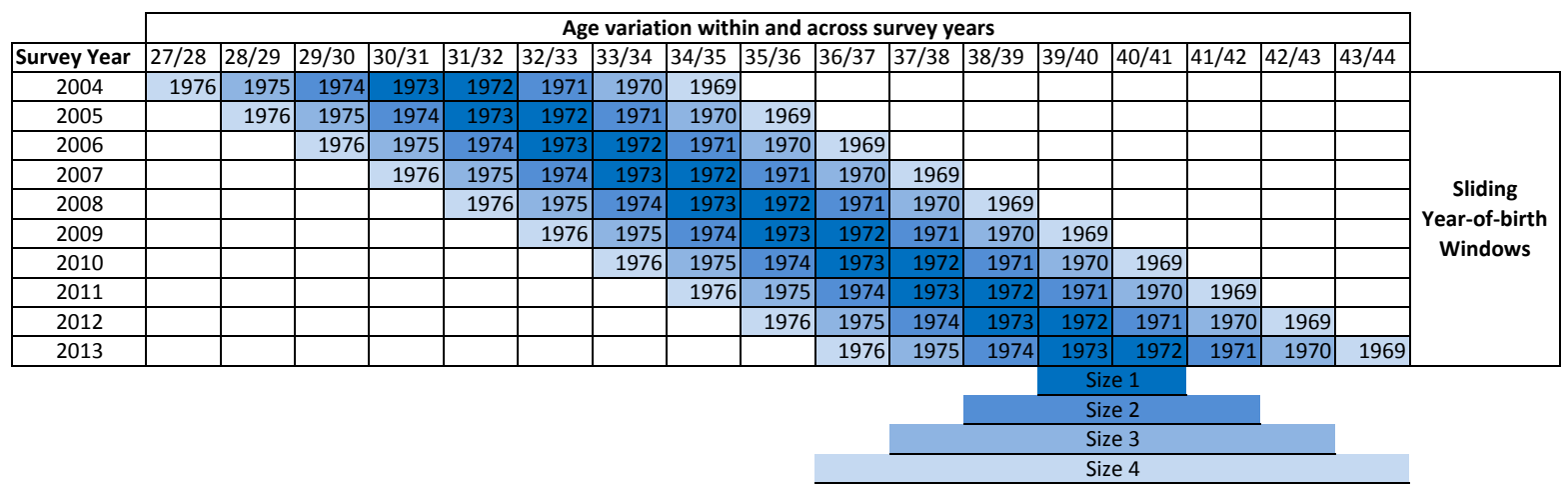

Figure 1: Estimation design. A visual representation.

size-2 window compares the outcomes of those born in 1971-1972 to the outcomes of those born in 1973-1974. The size-3 window compares the outcomes of those born in 1970-1972 to the outcomes of those born in 1973-1975. Finally, the largest window performs a comparison between 1969-1972 and 1973-1976. This is actually a simple regression discontinuity design (RDD) implementation as we have a conditional expectation function which is discontinuous at a particular value of an observable forcing variable. The outcomes of interest are school attainment, earnings, labor force participation, employment, and unemployment. We report the results at three stages. At the first stage, we perform the regressions for males. At the second stage, the same analyses are performed for females. Finally, the regressions are performed for males based on placebo treatment dates. Since compulsory military service is binding only for males, we expect to see no effect on females as a consequence of the paid exemption reform. We also expect to see no effect for placebo treatment dates.

Difference in differences. Next, we design two separate difference-in-differences (DID) strategies to check the robustness of the estimates obtained with the direct approach. The first specification performs differencing between the policy margins across two consecutive years. The main motivation is as follows. The direct approach performs comparisons across entire years using a simple RDD design. A more refined strategy would set narrower analysis windows. However, as we explain above, although the reform date is set exogenously, it is likely to capture family background effects that can be correlated with the season of birth. One potential solution to avoid this problem is to perform a DID estimation designed as taking 
the difference between two narrowly defined observation windows across two consecutive years. We set a window defined over months of birth, say, 1 September 1972 - 30 April 1973. In this example, the window of analysis is 8 months symmetrically centered around the reform date 31 December 1972. To overcome the confounding season of birth effects, we compare the change in the labor market outcomes of eligible males born in this interval to the change in the labor market outcomes of the males born in the control interval defined as 1 September 1973 - 30 April 1974. The main identifying assumption here is that the season of birth effects are the same across these two windows. Our first DID specification (which we call SPEC 1) can be written as follows:

$$
y_{i, r, m, s}=\alpha+\beta \cdot T_{i}+\delta \cdot B_{i} \times T_{i}+\boldsymbol{\theta}^{\prime} \cdot \boldsymbol{X}_{i}+f_{r}+f_{s}+f_{m}+\epsilon_{i, r, s, m},
$$

where the dummy variable $T$ takes the value 1 if the year-of-birth period is $1972-1973$ and 0 if it is 1973-1974, while $B_{i}$ takes the value 1 if the month of birth is January and later months and 0 if it is December or preceding months. The other variables are defined as above. The main parameter of interest is $\delta$. Note that the variable $B$ is omitted from the regression since we also include the month-of-birth dummies.

In our empirical analysis, we perform this DID exercise for males over three different windows: (i) 8-month window defined as the birth-date interval 1 September 1972 - 30 April 1973, (ii) 10-month window defined as the birth-date interval 1 August 1972 - 31 May 1973, and (iii) 12-month window defined as the birth-date interval 1 July 1972 - 30 June 1973 . For robustness purposes, we also perform the DID analysis for females. Again, since the paid exemption reform is only expected to affect the outcomes of males, the DID estimation for females should not produce any impact.

In our second DID specification (which we call SPEC 2), we perform the second difference across gender categories rather than across years. Here, the key assumptions are that (1) the month-of-birth effects are symmetric for males and females - which is verified by Torun and Tumen (2015) - and (2) the labor market outcomes exhibit parallel trends across males and 
females around the reform date - which we assume. This DID specification can be written as follows:

$$
y_{i, r, m, s}=\alpha+\beta \cdot M_{i}+\delta \cdot B_{i} \times M_{i}+\boldsymbol{\theta}^{\prime} \cdot \boldsymbol{X}_{i}+f_{r}+f_{s}+f_{m}+\epsilon_{i, r, s, m}
$$

where the dummy variable $M$ takes the value 1 if the individual is male and 0 if female, while $B_{i}$ takes the value 1 if the month of birth is January and later months and 0 if it is December or preceding months. We use the same analysis windows as we do in SPEC 1.

Triple difference. Finally, we bring all three dimensions together and perform a triple difference analysis. So, the regression analysis now performs comparisons across birth months, across years of birth, and across gender categories. This is very similar to triple difference analysis performed by Di Pietro (2013). Since the compulsory military service is only expected to affect the outcomes of males, it might be interesting to set females as the baseline group and perform comparisons accordingly. The DID and triple difference analyses complement each other in the sense that the former shows whether we actually see an effect for males across years and with respect to females, while the latter brings all three pieces together. Our triple difference equation can be simply written as

$$
\begin{aligned}
y_{i, r, m, s}=\alpha & +\psi \cdot M_{i}+\beta \cdot T_{i}+\xi \cdot T_{i} \times M_{i}+\phi \cdot B_{i} \times M_{i}+\gamma \cdot B_{i} \times T_{i} \\
& +\delta \cdot B_{i} \times T_{i} \times M_{i}+\boldsymbol{\theta}^{\prime} \cdot \boldsymbol{X}_{i}+f_{r}+f_{s}+f_{m}+\epsilon_{i, r, s, m}
\end{aligned}
$$

where $M$ is a dummy variable taking 1 if the individual is male and 0 if female, the dummy variable $T$ takes the value 1 if the year-of-birth period is $1972-1973$ and 0 if it is 1973-1974, while $B_{i}$ takes the value 1 if the month of birth is January and later months and 0 if it is December or preceding months. All the other variables are defined as above. Our main parameter of interest in this specification is, again, $\delta$. 


\section{Results and Discussion}

\subsection{Main Results}

In the previous sections, we explain that a four-year college degree allows young males to perform a more preferable military service. For that reason, the compulsory military service in Turkey provides an extra incentive for males to attend college, whereas females are not affected by these regulations. In this section, we empirically examine whether this hypothesis is correct. If so, we expect the paid exemption law to reduce the college graduation rates among males who are eligible to benefit from the 1999 law compared to those who cannot benefit. We implement three different empirical strategies to investigate the effect of paidexemption law on school attainment and real earnings. Then, we perform robustness checks using the same three strategies and show that paid exemption law does not have any effect on females and, furthermore, placebo cutoff dates do not yield any meaningful results.

First, we estimate the regression Equation (4.1). Table (2) shows the estimated effect of paid exemption reform on school attainment of males. The sample includes males born around the cutoff date, December 31, 1972, from survey years 2004-2013. The dependent variable is the years of completed education in the first four columns and a binary indicator that takes the value 1 for college graduates and zero otherwise in the last four columns. The empirical model in the first and the fifth columns basically compares the school attainment of those who were born in 1972 to those who were born in 1973. We find that males born in 1972 have 0.26 years of education less than males born in 1973. We also find that the former group is less likely to have a college degree by 1.9 percentage points. Yet, this estimate is a combination of cohort effect and the treatment effect. For example, if there is an upward trend in school attainment across cohorts, then a decline with the magnitude 0.26 years will be a biased estimate. For that reason, we include more cohorts in the second, third, and fourth columns; the year-of-birth intervals 1971-1974, 1970-1975, and 1969-1976, respectively. As we have several consecutive cohorts in the sample, we also control for the trends in the year of birth. We still find negative

and statistically significant estimates in most specifications. The estimates from alternative 
specifications stay in the ballpark of a decline by $0.20-0.25$ years of education due to the paid exemption reform. The sixth, seventh, and eighth columns also confirm the negative effect of the law on college attainment. Figure (2) presents some visual evidence using the residuals from Equation (4.1). Although the regressions are performed over the year-of-birth trends for our baseline results reported in Table (2), we also repeat the same regressions by fitting the years of education trends over the quarter-of-birth and month-of-birth for the purpose of obtaining more refined evidence. In all three cases, we observe a statistically significant jump right at the cutoff point, which visually confirms the validity of our results.

Theoretically speaking, the net effect of the paid exemption law on individual earnings is ambiguous. As the paid exemption reduces the college attainment of young males, it may also reduce their earnings. On the other hand, those who benefit from the law do not suffer from the human capital depreciation as much as those who serve for 9 months or 18 months. Therefore, the net effect on the earnings is an empirical question. Table (3) shows the estimated effect of the paid exemption law on the real earnings of males. The structure of Table (3) is the same as Table (2) except that the last four columns restrict the sample to those with high school degree or above. In the first three columns, all estimates are negative and statistically significant. Yet, the estimated effect is very small and statistically insignificant in the fourth column. When we restrict the sample to those with high school degree or above, the estimates are not statistically significant. In Tables (4)-(6), we also examine the effect of the paid exemption law on employment status of young males. The sample includes males born around the cutoff date, December 31, 1972, from survey years 2004-2013. The dependent variable is a binary indicator for employment, unemployment, and labor force participation respectively. We do not find any significant effect of the law on any of these outcomes.

Next, using the same empirical methodology, we perform two placebo exercises. First, we repeat the previous two estimations for females. Since the regulations of military service do not provide any incentive for females, we do not expect the paid exemption law to affect their school attainments or wages. Table (7) shows that the paid exemption law does not have a statistically meaningful effect on the school attainment of females who were born in 1972 or 
before compared to females born in or after 1973. Similarly, we do not find any significant effect on real earnings of females in Table (8).

In Table (9), we set two different placebo treatment dates rather than the original one. The upper panel sets December 31, 1977 as the placebo cutoff date. Then for 2, 4, 6, and 8year windows, using the regression Equation (4.1), we estimate the effect of being born before December 31, 1977 on school attainment and log real earnings. We do not find any statistically significant effect except for the fifth column - which may be due to the cohort effect. Similarly, in the lower panel, we set December 31, 1978 as the placebo cutoff date. Again, we fail to find any meaningful effect of the placebo treatment. These two placebo exercises suggest the results in Table (2) and Table (3) are not driven by the estimation methodology.

Second, we apply the two difference-in-differences strategies and estimate the regression Equations (4.2) and (4.3) for the same outcomes as above. In these regressions, instead of controlling for year-of-birth trends, we focus on a very narrow window around the cutoff date December 31, 1972. We could basically compare the education and labor market outcomes of those who were born right before the cutoff date to those who were born right after the cutoff date. Yet, the difference between the two groups may reflect the season of birth effects. Torun and Tumen (2015) show that individuals born in the last quarter of a year have higher education levels and better labor market outcomes than those born in the first quarter of the year. In order to incorporate this season of birth effects, we difference out the January effect across years in the first specification and across gender categories in the second specification. Therefore, the main identifying assumption is that the season-of-birth effects are the same across two consecutive years and gender categories. ${ }^{11}$

Table (10) shows the estimated effect of the paid exemption law on the school attainment of males for the SPEC 1 model. For all sample configurations, we find that males who were born in the late 1972 have $0.14-0.24$ years of education less than males born in early 1973, after controlling for the season-of-birth trends. The last three columns show that the law reduces

\footnotetext{
${ }^{11}$ The alternative is to set a much longer observation window and control for the month-of-birth effects instead of performing differencing. Our findings show that the results are overly sensitive to changing the window size even slightly. To avoid such an inconsistency, we avoid this strategy and instead focus on the differencing strategy.
} 
the college attainment by $0.2-0.6$ percentage points among males. Table (11) shows the estimated effect on real earnings of males using the SPEC 1 difference-in-differences strategy. The estimates are all negative and statistically significant in the first three columns. When we restrict the sample to those with a high school degree and above, the estimated effect on the real earnings is again negative and statistically significant.

Table (12) shows that the paid-exemption law does not affect the school attainment of females who were born in late 1972 in a statistically meaningful manner compared to females born in early 1973 - again under the SPEC 1 model. Similarly, in Table (13), we do not find any significant effect on real earnings of females using the same difference-in-differences strategy. Overall, the results from the difference-in-differences strategy are very similar to those from the regression Equation (4.1). We find negative effect of the paid exemption law on educational attainment - college attendance in particular. We also find suggestive evidence that the law reduces the real earnings of males through the decline in college attendance.

We repeat the difference-in-differences analysis under the SPEC 2 model, in which we difference out the eligiblity margin with gender as we describe in Equation (4.3). For the education regressions, we find that the policy reform reduces years of schooling by approximately 0.16 years and the college gradaution probability by $0.2-0.4$ percentage points among males, relative to females [see Table (14)]. Results reported in Table (15) also point out to a suggestive decline in wages. These findings are mostly consistent with the other findings discussed above.

Finally, we perform a triple-difference estimation by adding another layer to the difference-indifferences estimation. Remember that, in the DID methodology SPEC 1 model, males born around December 31, 1972 constitute the treatment group. Then, we incorporate males born around December 31, 1973 as the control group and we assume that the season of birth effects are the same across two groups. ${ }^{12}$ Now, we relax this assumption too. We allow the season of birth effects to change across two groups. Yet, we assume that the change in the season of birth effects across two groups are the same among males and females. Tables (16) and (17)

\footnotetext{
${ }^{12}$ In other words, we assume that, in the absence of the law, the difference in socio-economic conditions between males born in late 1972 and early 1973 would be the same as the difference between males born in late 1973 and early 1974 . This is the common trends assumption typically used in DID estimations.
} 
estimate the regression Equation (4.4) and document the estimated effect of the law on school attainment and log real earnings of males using a triple difference strategy. The results are very much in line with those from the previous regression models. The paid exemption law reduces education of males by $0.05-0.13$ years among males, and their likelihood of college attainment by $0.2-0.5$ percentage points. Table (17) presents suggestive evidence that the law reduced the real earnings of males slightly, if any.

We also perform several additional regressions. First, as a falsification check, we test whether we observe any statistically significant effect of the reform on high school graduation and the results do not represent a coherent story - as expected. As a complementary analysis, we condition our earnings regressions on those who only have a high school degree; we again find no effect [see Table A5 in the Online Appendix]. Second, we drop individuals of age 27-29 and perform our regressions for individuals of age 30 and above to see if the results change. We observe no meaningful change in our estimates both quantitatively and qualitatively [see Table A3-A4 in the Online Appendix]. Third, our regressions on earnings focus only on salaried workers, which may be subject to selection problems. To address this concern, we test whether the wage-employment likelihood has been affected from the paid exemption reform and we found no effect, which suggests that focusing on salaried workers does not have a potential to generate a non-negligible bias on our estimates [see Table A2 in the Online Appendix]. Finally, we also check whether the results are concentrated over a specific region along the earnings distribution. We perform separate regressions for upper and lower halves of the earnings distribution. We find that the effect of the program is most visible within the lower half of the earnings distribution, which potentially suggests that those who have benefited from the reform are the ones who enroll in college for postponing military service rather than seeking higher wages [see Table A6 in the Online Appendix]. It should be noted, however, that wage is an endogenous outcome and, therefore, this result should be interpreted cautiously. 


\subsection{Further Analysis}

Our main focus in the analysis presented and discussed above is to estimate the intentionto-treat effect of the paid exemption reform on educational outcomes. We then performed additional regressions to check whether there are also any reflections on wages. The main result is that the paid exemption reform has generated a reduction in educational attainment, which further generates a suggestive decline in wages among the eligible males relative to the wages of the observationally equivalent ineligible males. In this subsection, we construct an instrumental variable analysis in which we use the decline in educational attainment as a consequence of the paid exemption reform as an instrument to estimate the impact of education on earnings. This type of instrumental variable (IV) strategies are often used in the related literature [see, e.g., Maurin and Xenogiani (2007)].

We construct our IV regressions on the "first specification (SPEC 1)" of our difference-indifferences analysis [see Equation (4.2)], in which we estimate the impact of being born on or before December 31st in two consecutive years and then difference out these two numbers to extract the intention-to-treat effect of the reform by netting out the month-of-birth effect due to being January-born. The related literature [see, e.g., Harmon and Walker (1995), Oreopoulos (2006), Heckman, Lochner, and Todd (2006), and Maurin and Xenogiani (2007)] generally reports estimates in the ballpark of $0.07-0.15 \log$-point increase in earnings as a consequence an additional year of schooling. Table (18) reports our IV estimates. The results suggest that our estimates are in the interval of $0.16-0.23$ - all statistically significant. As a robustness check, we also report that the IV estimates for females are mostly statistically insignificant, as expected.

Our IV estimates for the returns to schooling are larger than the standard estimates reported in the literature. We are a bit cautious about attributing strong meanings to these estimates, but we still have two plausible explanations. First, the paid exemption reform generates a variation of schooling at the college level. Maurin and Xenogiani (2007) perform a similar IV analysis and report estimates around 0.13 , but the education variation in their analysis is at the 
high school level. This might be one explanation. Second, by the nature of our measurement of years of schooling, we do not see exact changes in education at yearly increments. What we observe instead is the completed education levels (i.e., high school, college, etc). We convert these degrees into years of schooling as we describe in the Data Appendix. As a result, changes in educational attainment as a consequence of the reform drop college enrollers to high school level for eligible males. This suggests that our estimates potentially capture the "sheepskin effect" of college education in addition to the standard years of schooling effect. This can also explain our high estimates. Also, since individuals can also defer the military service through government service for a certain period, the paid exemption may have changed individuals' behavior through channels other than education. At the end, we would like to emphasize that we still prefer to interpret our earnings estimates as "suggestive."

\section{$6 \quad$ Framing and Interpreting the Results}

It should be acknowledged that the results need some framing in terms of the generalizability of the estimates over the entire population. In Turkey, the high school education typically ends at age 18 and, for a student entering the university/college right after high school graduation, the normal college-graduation age is 22. Around 40 to 50 percent of high school graduates, who choose to enroll in college, get into college in their second or third trials in the collegeentrance exam. ${ }^{13}$ For these students, the college-graduation age is 23 or 24 . Many universities also offer a curricula in English and these universities typically offer an additional year of education for English preparation-compulsory for the students who cannot pass an exam measuring fluency in English. It is clear that a non-negligible fraction of those who enroll in college graduate at age 24 or 25 . It should also be noted that the military system in Turkey allows the high school graduates to defer their military service for up to 2 years and college graduates for an additional 2 years.

There is also a non-negligible number of college enrollers who switch universities by re-entering the college-entrance exam in their first or second year of college education. These students

\footnotetext{
${ }^{13}$ In Turkey, the college-entrance exam is given once in a year and many students fail to succeed the exam in their first trials.
} 
generally switch disciplines - say, from engineering to social sciences or from medicine to mathematics, etc.-and they re-start their college education rather than transferring the already finished coursework. In Turkey, individuals cannot defer their military service beyond age 29, unless they are enrolled in graduate programs. There are also many students who enroll in graduate programs after college graduation. Finally, there is also a small group of individuals who choose to unofficially escape from military obligations. The individuals in this small group are typically less educated and mostly live in an isolated way and work informally (i.e., without frequent contact with the authorities).

Given this mixed structure, it should be stated as a caveat that the group of individuals who still have not finished their military obligations by age 27 follow a rather unusual path and may not necessarily represent the path followed by the average student. In this sense, the generalizability of our estimates may be somewhat questionable. That said, given the above explanations, the fraction of individuals who somehow avoid finishing their military service by age 27 is not negligible either, which means that the paid exemption reform has a potential to generate a behavioral change that would lead to non-negligible adjustments in aggregate educational and labor market outcomes along the policy margin. Table A1 in the Online Appendix presents the recent higher-education enrollment statistics in Turkey. These statistics suggest that more than 20 percent of college students and students enrolled in higher education in general are of age 27 and above.

As we mention earlier, our empirical design focuses on estimating the intention-to-treat (ITT) effects, which describe the overall impact of the reform on all eligible males. Since the policy margin we analyze includes also the males who have already completed their military obligations, there is a need to frame our estimates as interpretable numbers. To convert our econometric estimates into concrete and interpretable numbers, we perform the following back-of-the-envelope calculations. The number of males in the age interval 27-29 in 1999 is approximately 1.6 million. The total number of males who benefited from the paid exemption reform is approximately 100,000. This suggests that roughly 1 in every 16 eligible males actually benefited from the paid exemption opportunity-about 6.3 percent. Our years of 
schooling estimates are in the range of -0.15 to -0.20 , which means that our coefficients can be translated into an effective 2-3 years decline in schooling among the ones who benefited from the reform. We also find that this decline operates through declines in college graduation rates. The interval for our college-graduation probability estimates is from -0.006 to -0.009, which can be translated into declines in college-graduation probabilities in the interval of 9.5-14.5 percentage points. We acknowledge that these estimates are a bit high especially for the years of schooling estimates. We believe that there are two main reasons driving up the estimates. First, we do not observe the exact years of schooling; instead, we observe the completed degree and then convert the degree into the years of schooling using an approximation [see the Data Appendix]. Think of a high school graduate who enrolls in college for the purpose of deferring his military service. We observe him as having 15 years of schooling if he finishes college and 11 years if he drops out of college. These big jumps in the data may be generating an amplification in the response of the derived years of schooling variable. Second, males of age 27-29, who still enroll in college for the purpose of deferring military service, likely have low levels of attachment to pursuing college education. This suggests they will be much more likely to leave college in response to the exemption reform than the average male college student, which may again be generating an amplified response. To sum up, a combination of measurement and selected-sample issues may be generating high estimates in educational outcomes. We further document some reflections on wages in the sense that reduced college graduation rates have negatively affected the wage outcomes as a consequence of the paid exemption reform. But, we prefer to put only a modest emphasis on wage outcomes. Since some of our wage regressions yield estimates which are not statistically meaningful, we interpret our wage regressions as being "suggestive" rather than conclusive.

These results can be interpreted in light of the findings reported in the related work in the literature. In particular, the nature of the results reported in Maurin and Xenogiani (2007) is very similar to ours. Maurin and Xenogiani (2007) argue that although the literature generally focuses on supply-side sources of variation in education (such as proximity to schools and school-leaving ages), policies focusing on changing the benefits of attending school can also 
be quite effective. Using the 1997 reform in French, which abolishes conscription, they find that education outcomes have worsened among young males as the incentive to stay in school for the purpose of avoiding military service has disappeared. Wage outcomes have also been negatively affected. Our results are similar in spirit. We also show that compulsory military service may be providing incentives to stay enrolled in school, while a paid exemption reform can erode this incentive and worsen educational outcomes. Our results are a bit more specific than the results reported by Maurin and Xenogiani (2007), since the reform applies to only those who are still enrolled in school at age 27 and above. ${ }^{14}$ We also show that there is a suggestive wage reduction, since the college-graduation rates have declined among the eligible group after the reform.

Overall, our results suggest that college enrollment rates can be improved by implementing policies increasing the short-term pecuniary or non-pecuniary benefits of pursuing higher education. It is well-known in the literature that college graduates in general have better labor market outcomes than the high school graduates; thus, such policies can directly lead to improvements in post-school outcomes. Although many countries have already abolished compulsory military service, many others - mostly with strong army traditions - still implement conscription and debating the possibility of abolition and/or reforming the conscription system. These results also include important lessons for countries considering the reform of military conscription. The typical reform options for the countries with conscription are $(i)$ abolition of conscription, (ii) shortening the duration of service, (iii) professionalizing the army, $(i v)$ voluntary service, and $(v)$ unarmed public service option. Each of these options offer possibilities for relaxing (in differing degrees) the military service constraints for young males. The policy reform that we analyze also relaxes these constraints for a group of individuals and the results suggest that policy mechanisms providing incentives to stay enrolled in school have a potential to improve educational and labor market outcomes. These results can be generalized to a wide range of countries implementing compulsory military service.

\footnotetext{
${ }^{14}$ It should also be noted that the individuals who can benefit from the reform in our paper are potentially relatively well-off and have better family backgrounds.
} 


\section{Concluding Remarks}

In this paper, we study the overall effectiveness of a reform that allows for paid exemption from compulsory military service on the schooling and labor market outcomes of the eligible males in Turkey. The paid exemption option is provided to men-with a law enacted in November 1999 - who were born on or before December 31, 1972. Those who were born on January 1, 1973 or after are ineligible. This natural experiment enables us to set up an empirical design to estimate the effect of the paid exemption reform on the educational and labor market outcomes of the eligible men. Since we do not exactly know who have benefited from the reform, our estimates should be interpreted as the "intention-to-treat" effect — as the empirical analysis is constructed based on the initial assignment of the treatment, not on the treatment eventually received.

Compulsory military service imposes certain restrictions on the education and employment decisions of young men. This is especially a concern for the countries in which the duration of service is typically long - such as Turkey. The empirical exercise we perform allows us to understand, at least partially, how compulsory military service affects education and labor market outcomes. We find that the paid exemption reform reduces the educational attainment for the eligible men. In particular, it reduces the probability of receiving a college degree or above. This suggests that compulsory military service provides incentives to stay enrolled in college. We also find that there is a suggestive decline in the labor market earnings of eligible men. We conjecture that the decline in earnings is due to the decline in school attainment.

Taken at face value, our findings suggest that removing the compulsory service in Turkey will likely reduce educational attainment for those who stay enrolled to defer their military obligation. This is in line with Maurin and Xenogiani (2007), who show that the abolition of compulsory military service in France led to a reduction in educational attainment among males and, consequently, in earnings. In a similar spirit, our findings suggest that part of the males who are born on or after the reform cutoff-i.e., January 1, 1973-would have left school if they were also eligible for paid exemption. 


\section{A Data Appendix}

In this section, we provide a detailed description of the concepts we have defined throughout the paper as well as the variables we have used in the regressions.

\section{General Definitions:}

- Reform cutoff date: The paid exemption reform has a cutoff defined in terms of birth date. Specifically, males born on or before December 31, 1972 are eligible for the reform, while those born on or after January 1, 1973 are ineligible.

- Analysis window: To perform an empirical comparison between the eligible versus ineligible males, we set alternative analysis windows centered around the cutoff date. The OLS analysis sets the windows in terms of the year-of-birth variable. As Figure (1) describes, the small, medium, and large windows are set as 1972-1973, 1971-1974, and 1970-1975. The DID and triple difference analyses center the windows around the cutoff date in terms of the month-of-birth variable. These smaller windows are symmetrically defined around the cutoff date as 8-month, 10-month, and 12-month intervals. For example, the 8-month interval is set as September 1972-April 1973.

- Before the cutoff $(B=1)$ : The treatment group includes males born on or before December 31. These are the males who are eligible to benefit from the paid exemption reform.

- After the cutoff $(B=0)$ : The control group includes males born on or after January 1. These are the ineligible males.

- Treatment period $(T=1)$ : This variable is used in the DID and triple difference analyses. It is defined in terms of the year-of-birth variable and includes the ones who are born between July 1, 1972 and June 30, 1973.

- Control period $(T=0)$ : It includes the ones who are born between July 1, 1973 and June 30, 1974. 
- Gender $(M)$ : The gender variable is defined as the dummy variable $M$ taking 1 if the individual is a male and 0 if female.

- Reform effect (DID - SPEC1) $(B \times T)$ : This is the variable that we use in the SPEC1 DID regressions to identify the intention-to-treat effect of the paid-exemption reform on the educational and labor market outcomes of the eligible males. The cross product reflects the usual spirit of the difference-in-differences approach.

- Reform effect (DID - SPEC2) $(B \times M)$ : This is the variable that we use in the SPEC2 DID regressions to identify the intention-to-treat effect of the paid-exemption reform on the educational and labor market outcomes of the eligible males. The cross product reflects the usual spirit of the difference-in-differences approach.

- Reform effect (triple difference) $(B \times T \times M)$ : This is the variable that we use in the triple-difference regressions to identify the intention-to-treat effect of the paid-exemption reform on the educational and labor market outcomes of the eligible males in comparison to the outcomes of females.

- Unemployment: Unemployment is described by a dummy variable taking 1 if the worker is not working but actively seeking for a job and 0 otherwise. Notice that this variable describes the unemployment-to-population ratio, rather than the traditional unemployment rate.

- Employment: Employment is described by a dummy variable taking 1 if the worker is employed and 0 otherwise. This variable describes the employment-to-population ratio.

- Labor force participation: The labor force participation variable is described by a dummy variable taking 1 if the worker is either unemployed or employed, and 0 if the worker is not in labor force.

- Years of schooling: The education variable is described in 6 categories in the Turkish Household Labor Force Survey: 1 - no degree, 2 - primary school, 3 - middle school, 4 high school, 5 - vocational high school, and 6 - college or above. In the paper, we define the years of schooling variable by setting categories $(1,2)$ as 5 years, 3 as 8 years, $(4,5)$ as 
11 years, and 6 as 15 years. Note that this variable describes the years of "completed" education. The estimation is robust to the alternative calculations of years of schooling.

- College and above: We define this variable as a dummy taking 1 if the education category is 6 and 0 otherwise. It includes those who have two-year college degrees and graduate degrees. So, we cannot distinguish between two-year college graduates, four-year college graduates, and the ones with graduate-level degrees.

- Urban/rural status: Whether the worker resides in an urban versus rural area is described by a dummy variable taking 1 if the worker lives in an urban area and 0 otherwise. In the survey, an urban area defined as a residential area with population size above 20,000 .

- Trend: The time trend variable used in the OLS regressions are defined as the "yearof-birth" trends. It captures the trends in educational attainment and labor market outcomes across birth-year cohorts. We also include a quadratic term to capture possible non-linearities.

- Real earnings: The earnings variable describes the worker's monthly earnings including the monthly salary plus bonuses, performance pays, overtime pays earned in the corresponding month. The nominal earnings is deflated (taking 2004 as the base year) via the official CPI figures to generate real earnings.

Other general variables that do not need any description include age, region (NUTS2), and survey year dummies for 2004-2013. 


\section{References}

Angrist, J. D. (1990): "Lifetime Earnings and the Vietnam Era Draft Lottery: Evidence from Social Security Administrative Records," American Economic Review, 80, 313-336.

_ (1993): "The Effect of Veterans Benefits on Education and Earnings," Industrial and Labor Relations Review, 46, 637-652.

Angrist, J. D. And S. H. Chen (2011): "Schooling and the Vietnam-Era GI Bill: Evidence from the Draft Lottery," American Economic Journal: Applied Economics, 3, 96-118.

Angrist, J. D., S. H. Chen, And J. Song (2011): "Long-Term Consequences of VietnamEra Conscription: New Estimates Using Social Security Data," American Economic Review, $101,334-38$.

Angrist, J. D. And A. B. Krueger (1991): "Does Compulsory Schooling Attendance Affect Schooling and Earnings?" Quarterly Journal of Economics, 106, 976-1014.

(1994): "Why do World War II Veterans Earn More than Nonveterans?" Journal of Labor Economics, 12, 74-97.

Angrist, J. D. And J.-S. PIschke (2008): Mostly Harmless Econometrics: An Empiricist's Companion, Princeton, NJ: Princeton University Press.

Autor, D., M. G. Duggan, And D. S. Lyle (2011): "Battle Scars? The Puzzling Decline in Employment and Rise in Disability Receipt among Vietnam Era Veterans," American Economic Review, 101, 339-344.

BARr, A. (2015): "From the Battlefield to the Schoolyard: The Impact of the Post-9/11 GI Bill," Journal of Human Resources, 50, 580-613.

(2016): "Enlist or Enroll: Credit Constraints, College Aid, and the Military Enlistment Margin," Economics of Education Review, 51, 61-78.

Bauer, T. K., S. Bender, A. R. Paloyo, and C. M. Schmidt (2012): "Evaluating the Labor-Market Effects of Compulsory Military Service," European Economic Review, 56, $814-829$. 
(2014): "Do Guns Displace Books? The Impact of Compulsory Military Service on Educational Attainment," Economics Letters, 124, 513-515.

Bedard, K. And O. Deschenes (2006): "The Long-Term Impact of Military Service on Health: Evidence from World War II and Korean War Veterans," American Economic Review, 96, 176-194.

Bloom, H. S. (2008): "The Core Analytics of Randomized Experiments for Social Research," in The SAGE Handbook of Social Research Methods, ed. by P. Alasuutari, L. Bickman, and J. Brannen, London, UK: SAGE Publications Ltd., chap. 115-134.

Bound, J., D. A. JAeger, And R. M. BAKer (1995): "Problems with Instrumental Variables Estimation when the Correlation between the Instruments and the Endogenous Explanatory Variable is Weak," Journal of the American Statistical Association, 90, 443450.

Bound, J. And S. Turner (2002): "Going to War and Going to College: Did World War II and the G.I. Bill Increase Educational Attainment for Returning Veterans?" Journal of Labor Economics, 20, 783-815.

Buckles, K. S. And D. M. Hungerman (2013): "Season of Birth and Later Outcomes: Old Questions, New Answers," Review of Economics and Statistics, 95, 711-724.

Card, D. And A. R. Cardoso (2009): "Can Compulsory Military Service Raise Civilian Wages? Evidence from the Peacetime Draft in Portugal," American Economic Journal: Applied Economics, 4, 57-93.

Card, D. And T. Lemieux (2001): "Going to College to Avoid the Draft: The Unintended Legacy of the Vietnam War," American Economic Review, 91, 97-102.

De Tray, D. N. (1982): "Veteran Status as a Screening Device," American Economic Review, 72, 133-142.

Di Pietro, G. (2013): "Military Conscription and University Enrolment: Evidence from Italy," Journal of Population Economics, 26, 619-644. 
Dobkin, C. And R. Shabani (2009): "The Health Effects of Military Service: Evidence from the Vietnam Draft," Economic Inquiry, 47, 69-80.

Fisher, L. D., D. O. Dixon, J. Herson, R. K. Frankowski, M. S. Hearron, and K. E. Peace (1990): "Intention to Treat in Clinical Trials," in Statistical Issues in Drug Research and Development, ed. by K. E. Peace, New York, NY: Marcel Dekker, 331-350.

Galiani, S., M. A. Rossi, And E. Schargrodsky (2011): "Conscription and Crime: Evidence from the Argentine Draft Lottery," American Economic Journal: Applied Economics, $3,119-136$.

Grenet, J., R. A. Hart, And J. E. Roberts (2011): "Above and Beyond the Call: Longterm Real Earnings Effects of British Male Military Conscription in the Post-war Years," Labour Economics, 18, 194-204.

Harmon, C. And I. Walker (1995): "Estimates of the Economic Return to Schooling for the United Kingdom," American Economic Review, 85, 1278-1286.

Heckman, J. J., L. J. Lochner, And P. E. Todd (2006): "Earnings Functions, Rates of Return and Treatment Effects: The Mincer Equation and Beyond," in Handbook of the Economics of Education, ed. by E. A. Hanushek and F. Welch, New York: Elsevier, 307-458.

Hennekens, C. H., J. E. Buring, And S. L. Mayrent (1987): Epidemiology in Medicine, Boston, MA: Little, Brown and Company.

Imbens, G. W. AND W. VAn DeR KlaAuW (1995): "Evaluating the Cost of Conscription in The Netherlands," Journal of Business and Economic Statistics, 13, 207-215.

Maurin, E. And T. Xenogiani (2007): "Demand for Education and Labor Market Outcomes: Lessons from the Abolition of Compulsory Conscription in France," Journal of Human Resources, 42, 795-819.

Oreopoulos, P. (2006): "Estimating Average and Local Average Treatment Effects of Education when Compulsory Schooling Laws Really Matter," American Economic Review, $96,152-175$. 
Simon, C. J., S. Negrusa, And J. T. Warner (2010): "Educational Benefits and Military Service: An Analysis of Enlistment, Reenlistment, and Veterans' Benefit Usage 1991-2005," Economic Inquiry, 48, 1008-1031.

Torun, H. (2014): "Ex-Ante Labor Market Effects of Compulsory Military Service," Unpublished manuscript, Central Bank of the Republic of Turkey.

Torun, H. And S. Tumen (2015): "The Empirical Content of Season-of-Birth Effects: An Investigation with Turkish Data," Unpublished manuscript, Central Bank of the Republic of Turkey. 


\begin{tabular}{l|cc}
\multicolumn{3}{c}{ Summary Statistics (Means) } \\
\hline \hline & Male & Female \\
\hline Age & 35.90 & 35.81 \\
Years of schooling & 8.25 & 6.97 \\
No degree & 0.04 & 0.14 \\
Primary school & 0.46 & 0.56 \\
Middle school & 0.13 & 0.07 \\
High school & 0.11 & 0.08 \\
Vocational high school & 0.11 & 0.06 \\
College and above & 0.15 & 0.09 \\
Real Earnings & 700.75 & 694.35 \\
Employed & 0.87 & 0.31 \\
Unemployed & 0.08 & 0.03 \\
Not in labor force & 0.05 & 0.66 \\
\hline Sample share & 48.06 & 51.94 \\
\# of observations & 264,303 & 285,669 \\
\hline \hline
\end{tabular}

Table 1: Summary Statistics. This table reports the means of the key variables used in our analysis by gender category. The real earnings are denominated in 2004 Turkish liras. Our data comes from the survey years 2004-2013. We restrict attention to those who were born between 1969-1976. The age range of the sample is $27-44$ for both males and females. These are prime-age individuals; thus, the degree of labor market attachment is high relative to the other age groups, especially among males. The labor market variables (employed, unemployed, and not in labor force) are defined relative to the relevant population. In particular, "unemployed" is defined as the fraction of unemployed individuals in the population, rather than the rate of unemployment. The total number of observations is 549,972 . 


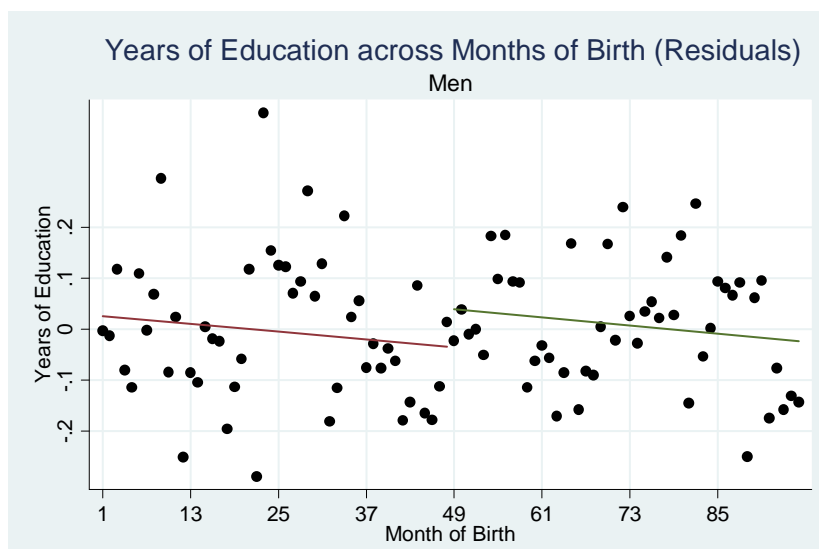

Years of Education across Quarters of Birth (Residuals)

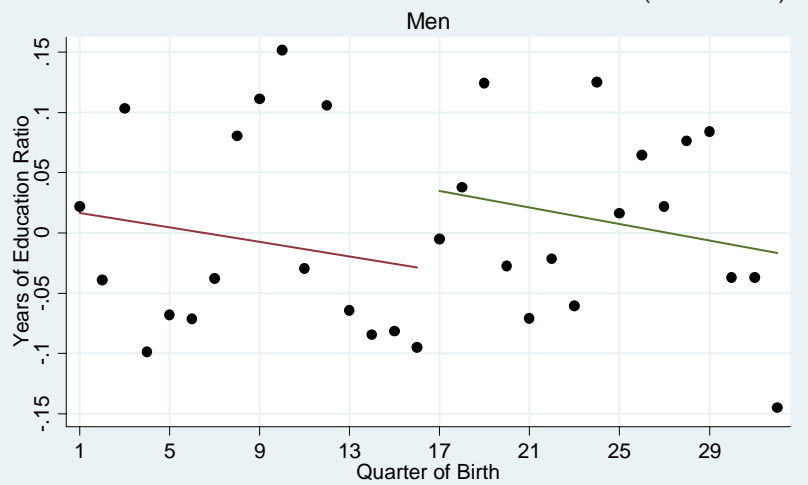

Years of Education across Years of Birth (Residuals)

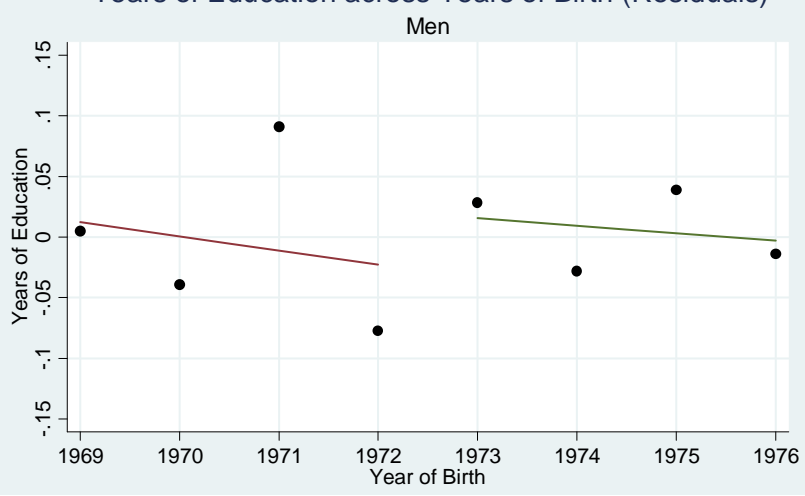

Figure 2: Visual evidence. These graphs provide a rough visualization for our results. We plot the residuals from our first specification over month-of-birth, quarter-of-birth, and year-of-birth trends. The sample contains individuals from survey years 2004-2013, who were born in 1969-1976. For the month-of-birth graph, those who were born in or before the month indexed by 48 (i.e., December 1972) are treated. For the quarter-of-birth graph, those who were born in or before the quarter indexed by 16 (i.e., Q4-1972) are treated. 


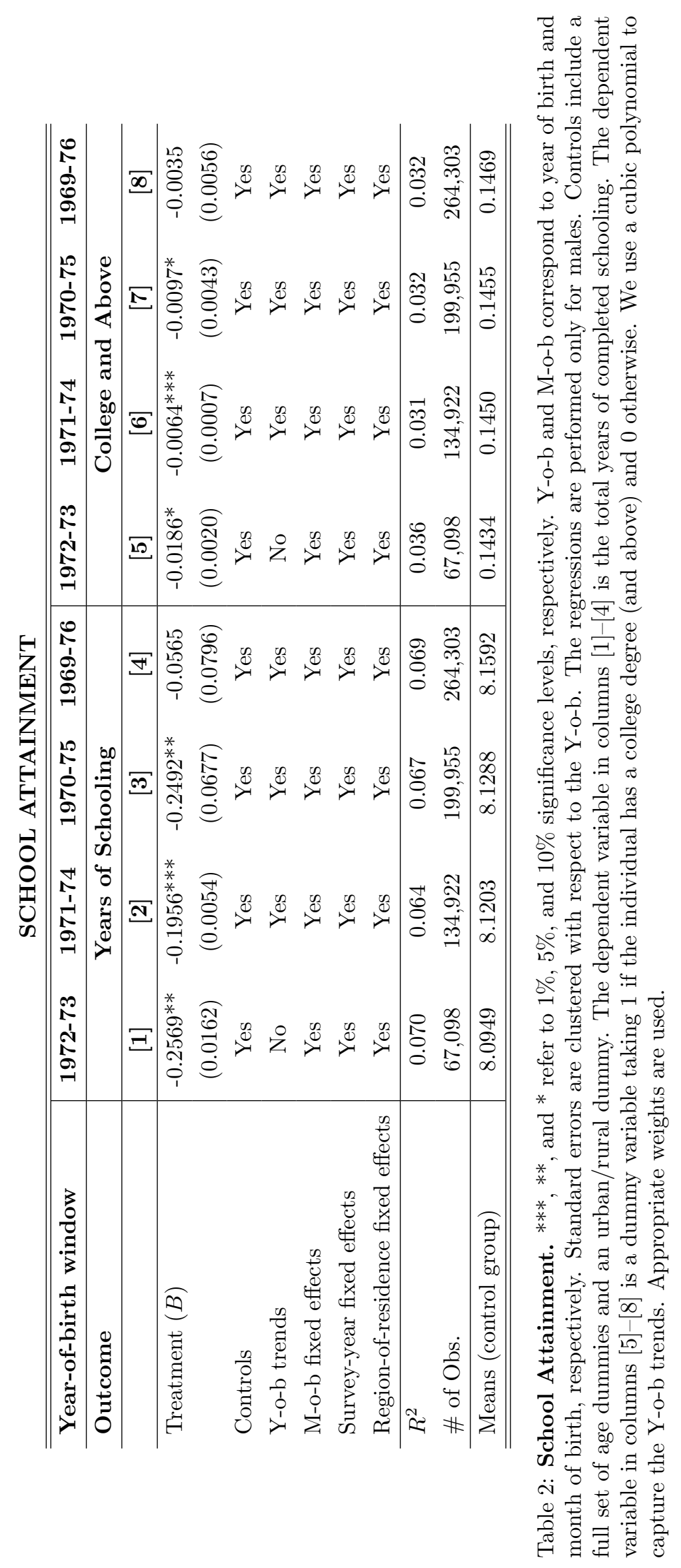




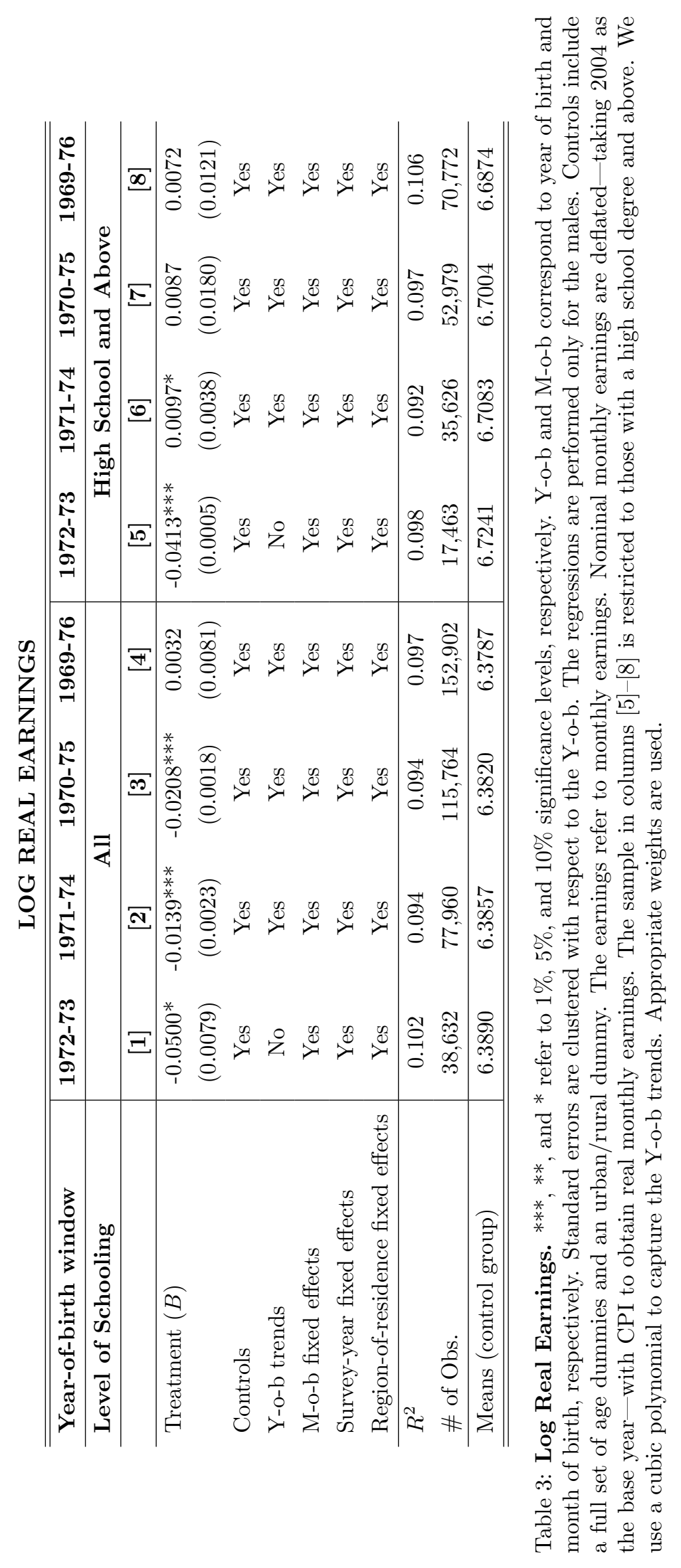




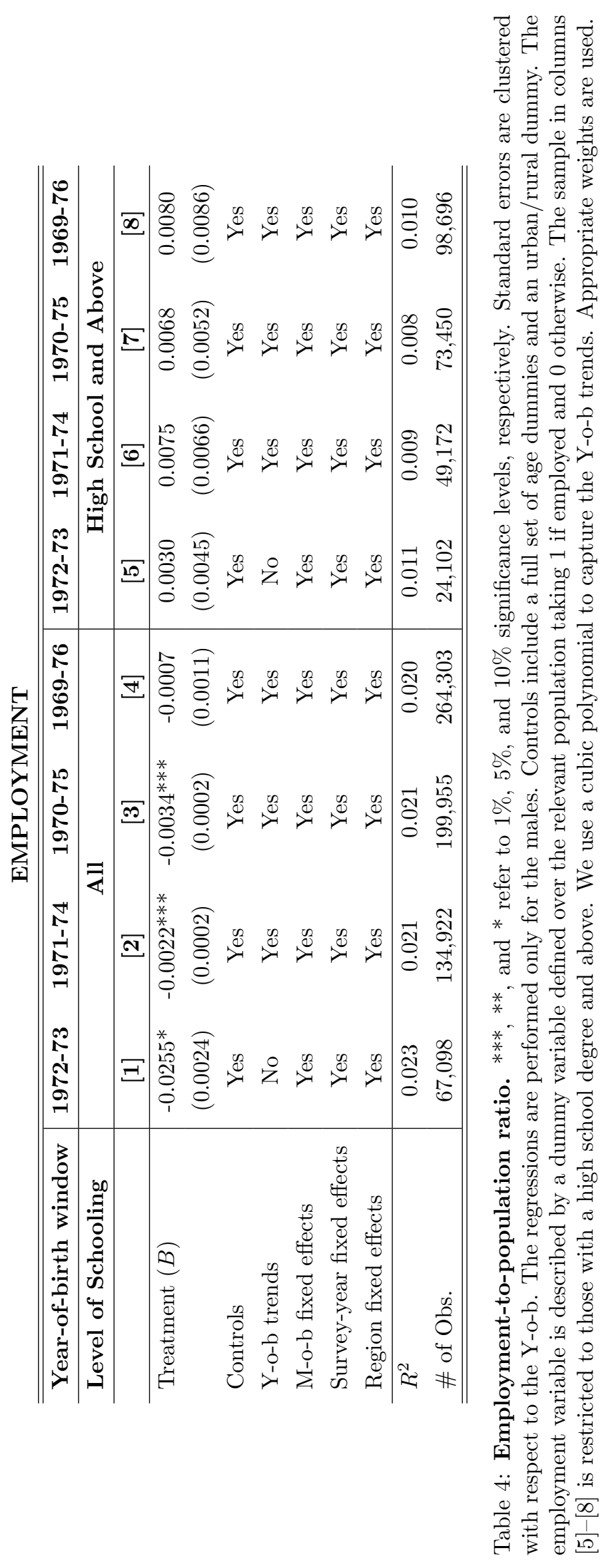




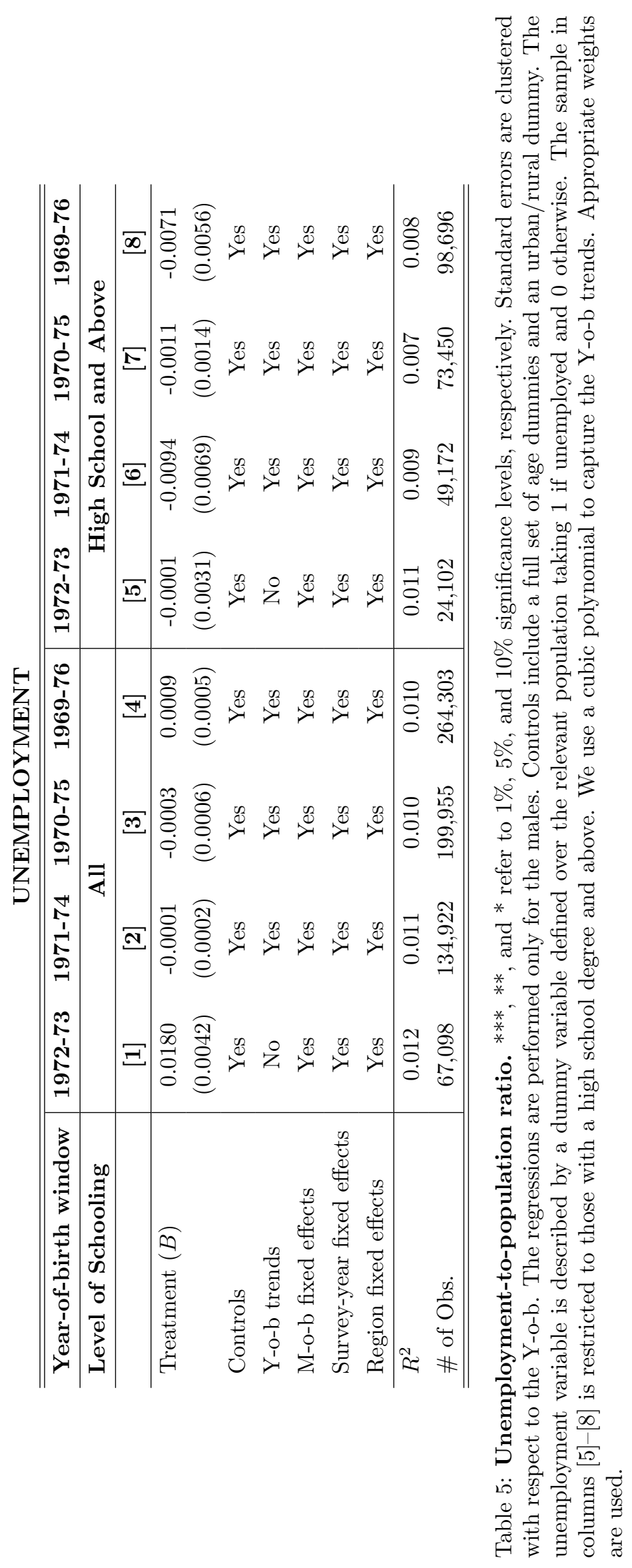




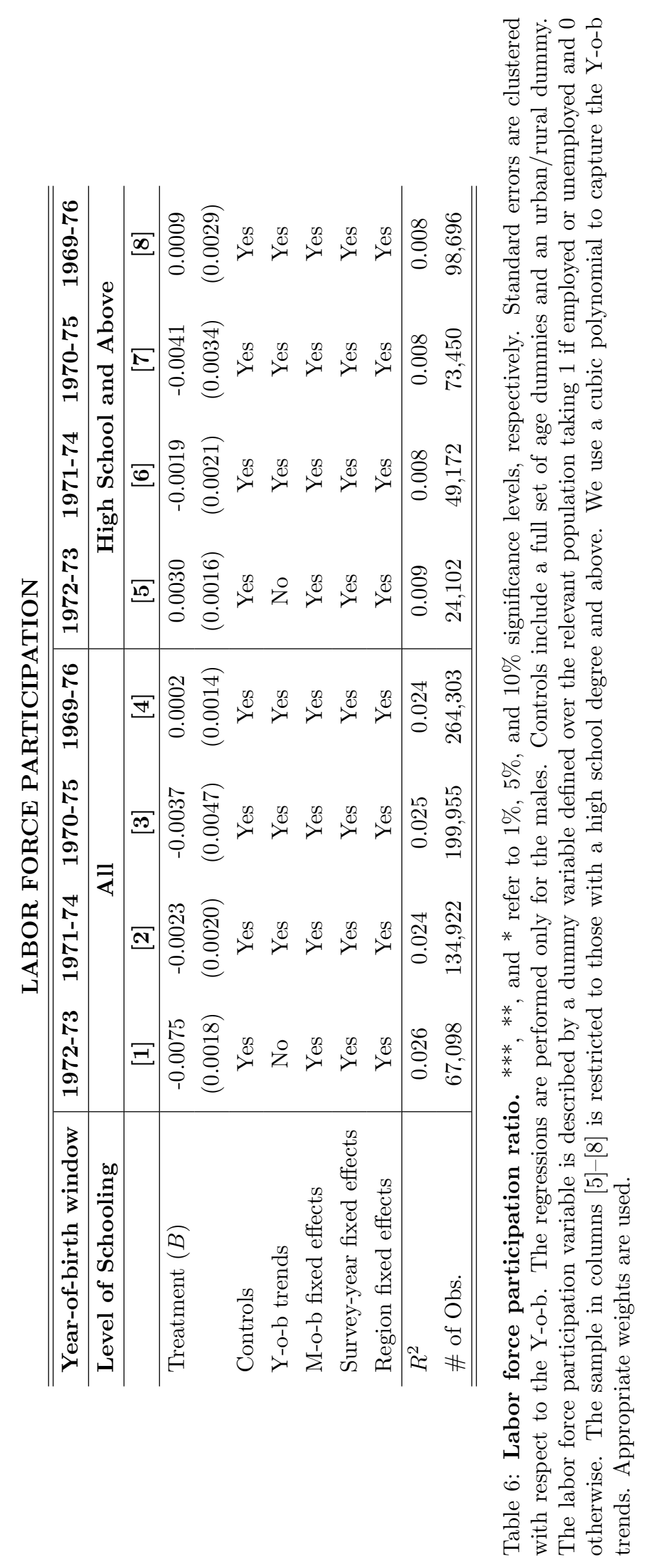




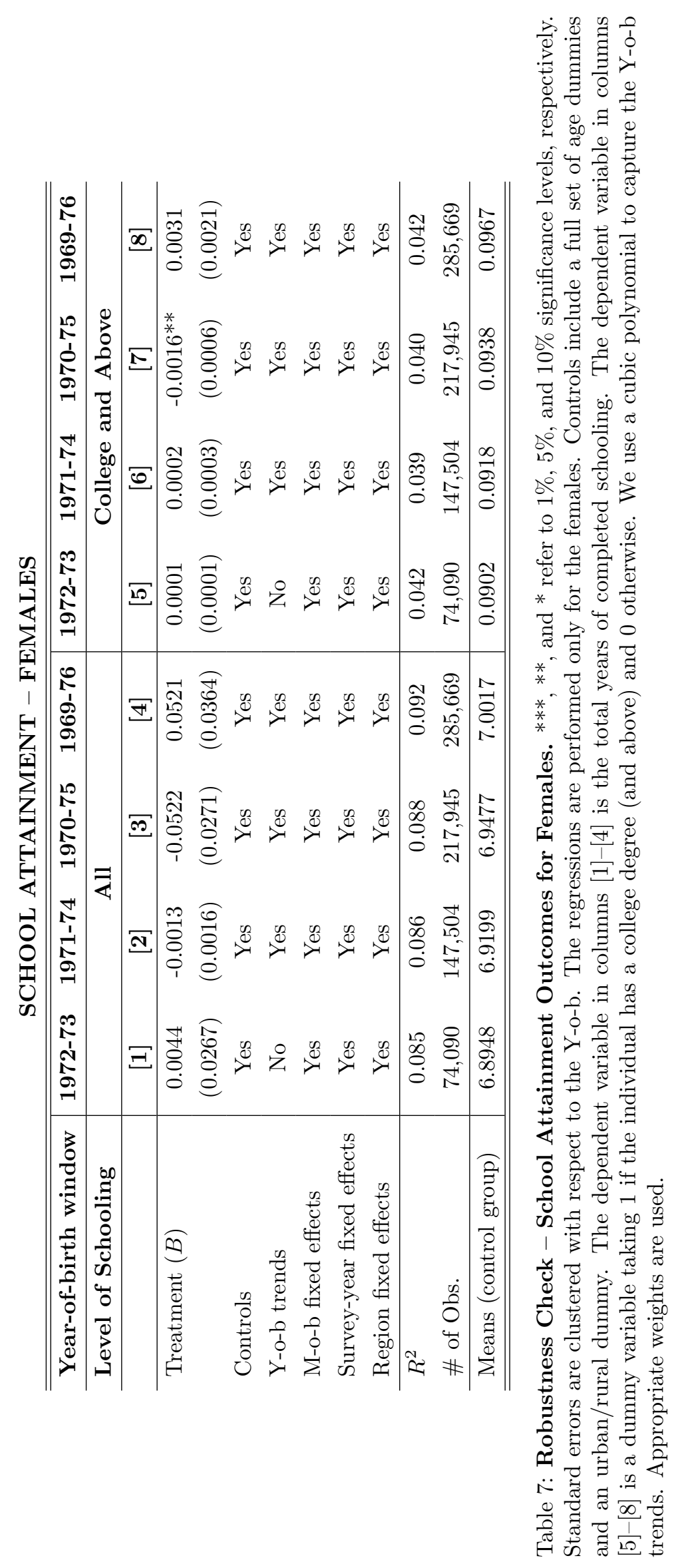




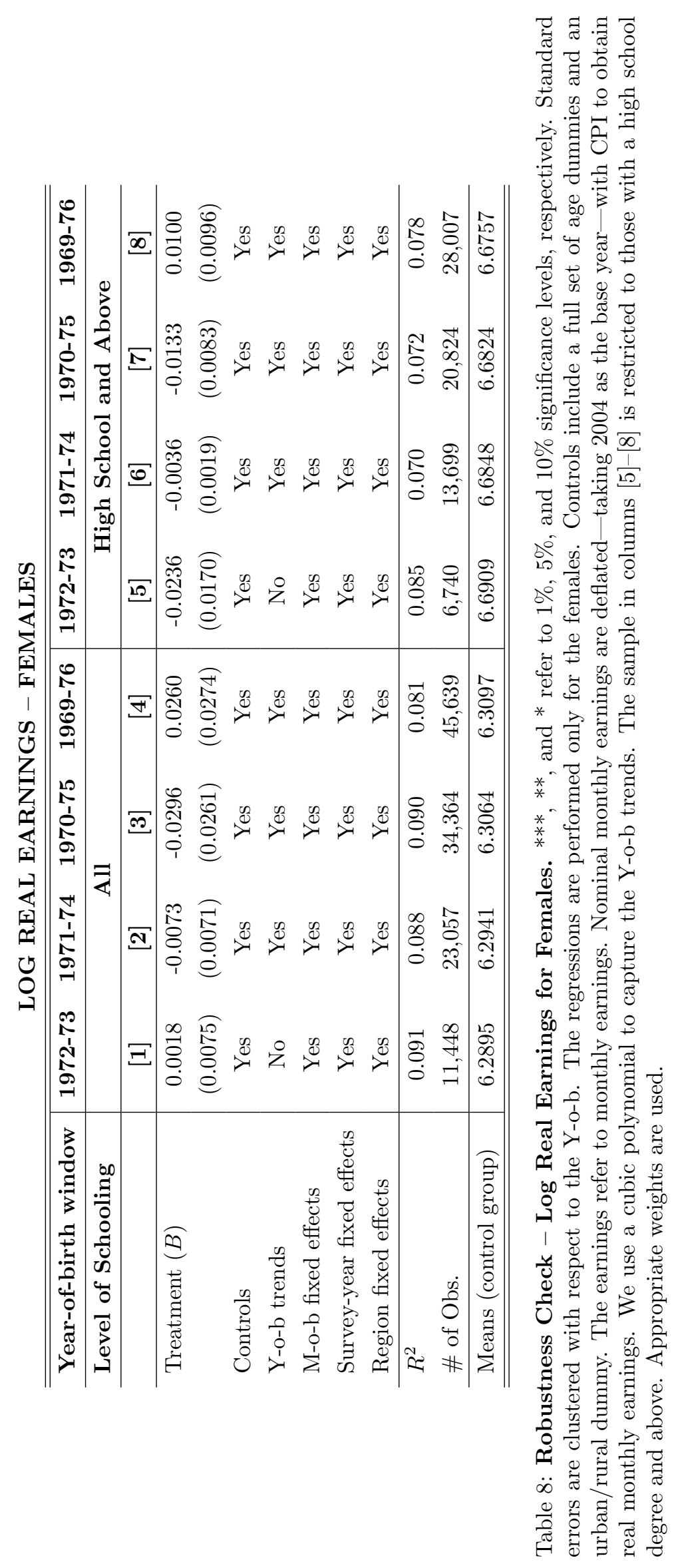




\section{专吾弯 \\ 윰

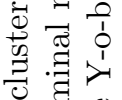

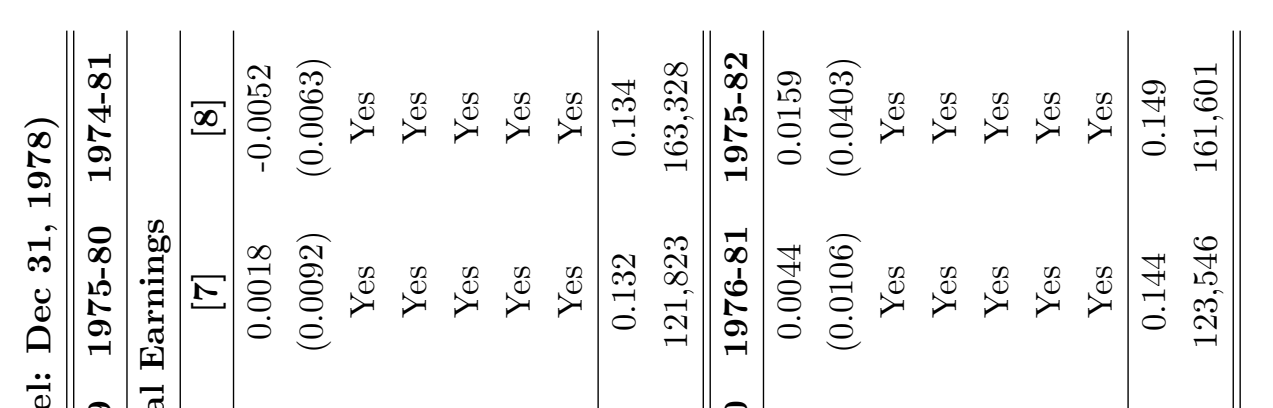

을

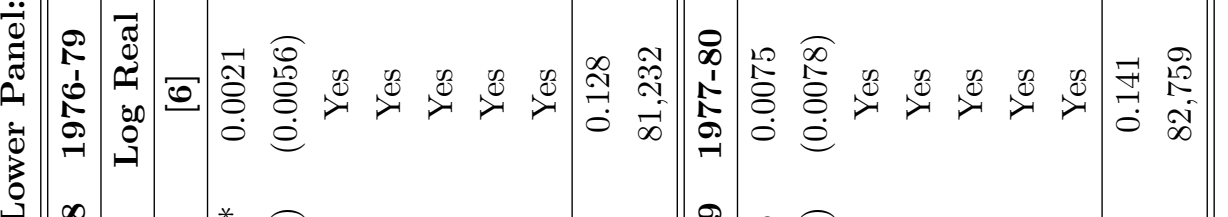

อ

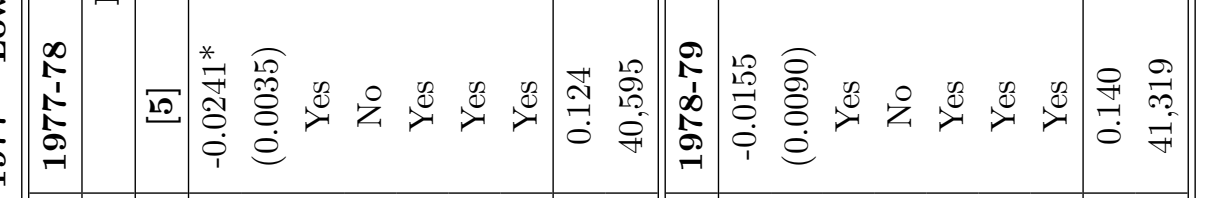

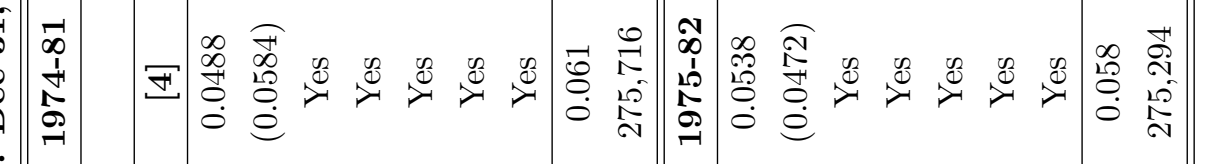

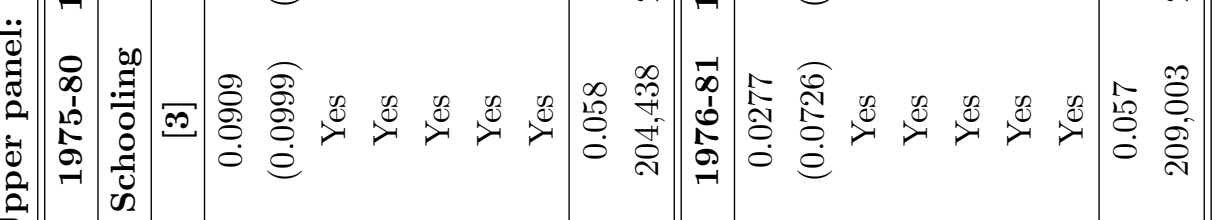

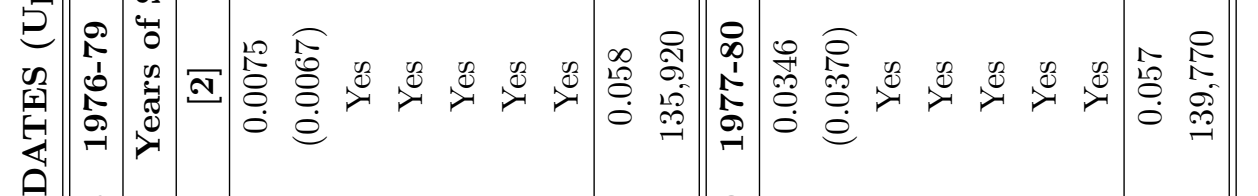

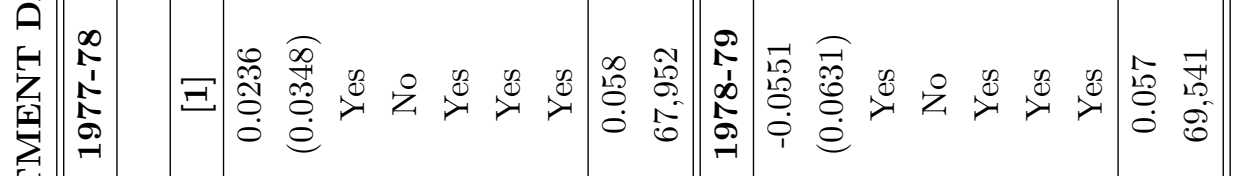

.

क्ष

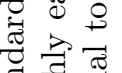

焉

궁

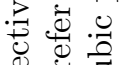

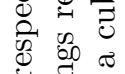

s 局学

造

o

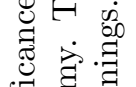

灵

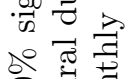

응

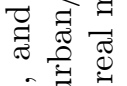

ㅇํㄹ

so

$7 \pi \circ$

密

*

学总

* -

* $\begin{array}{cc}0 \\ *\end{array}$

* *

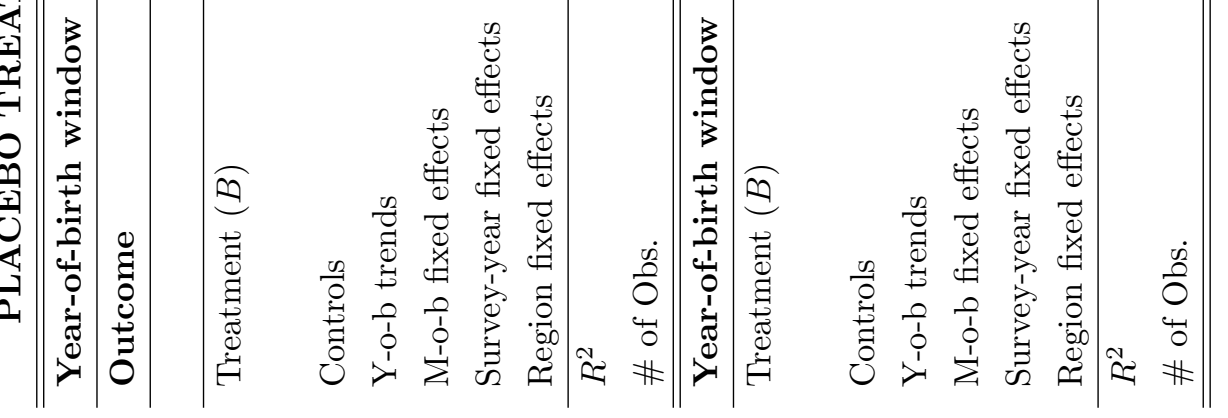

$\dot{0} \approx$

诺

ค.

눙

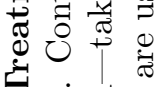

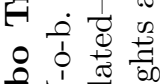

웅

蛋

A

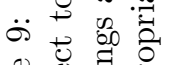

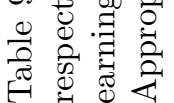




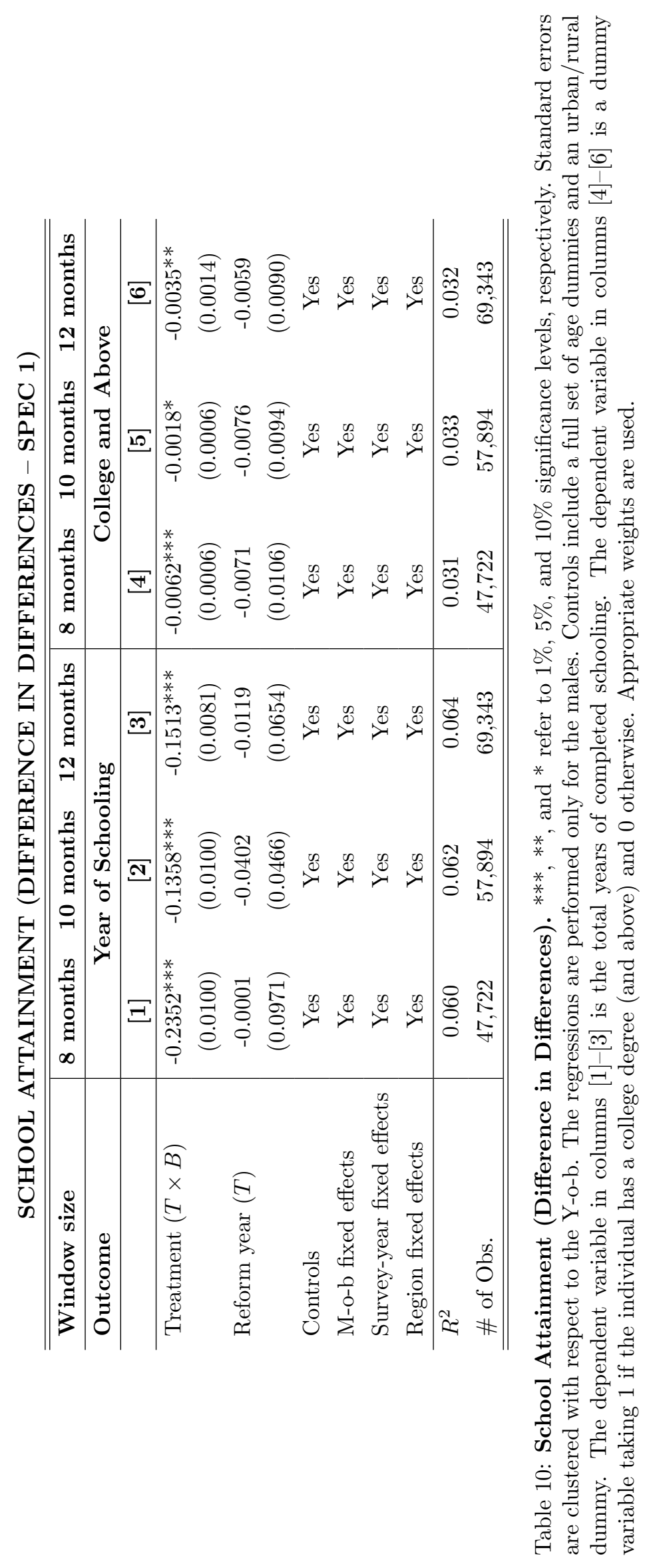




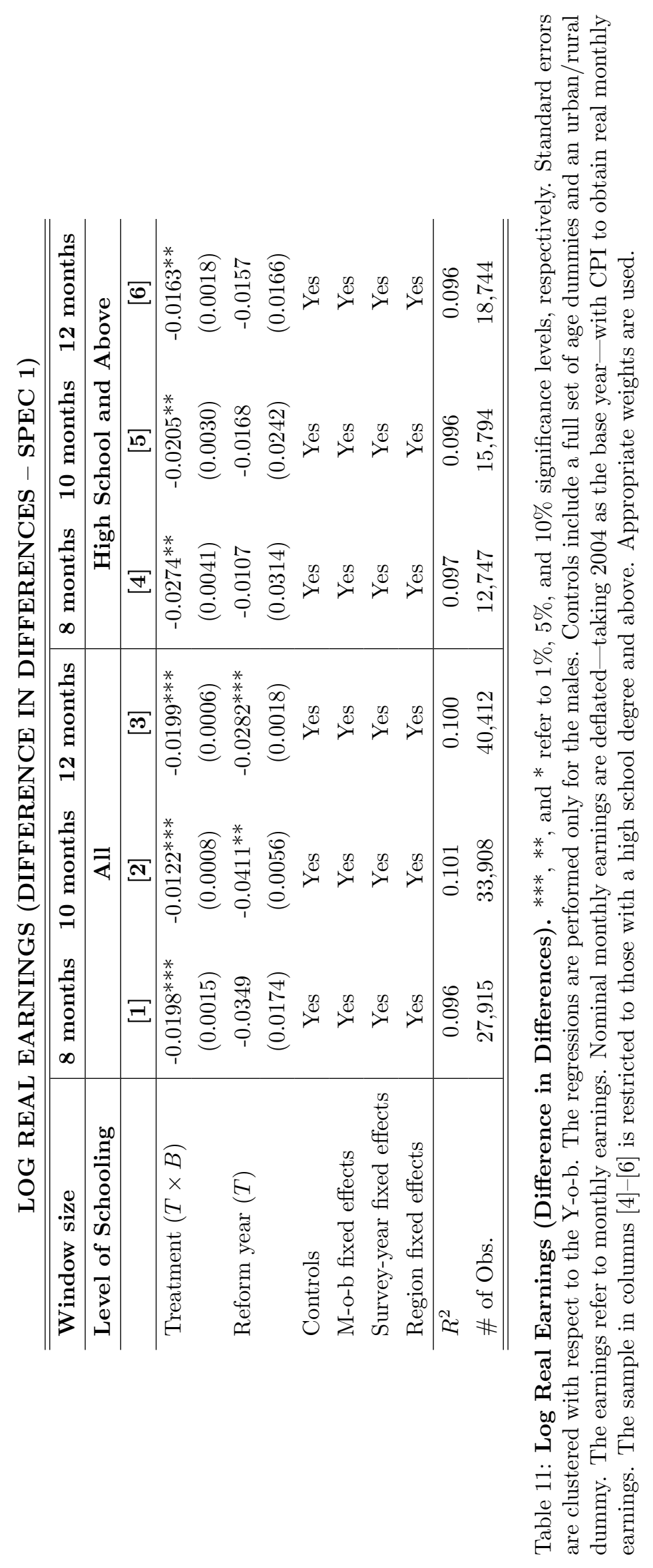




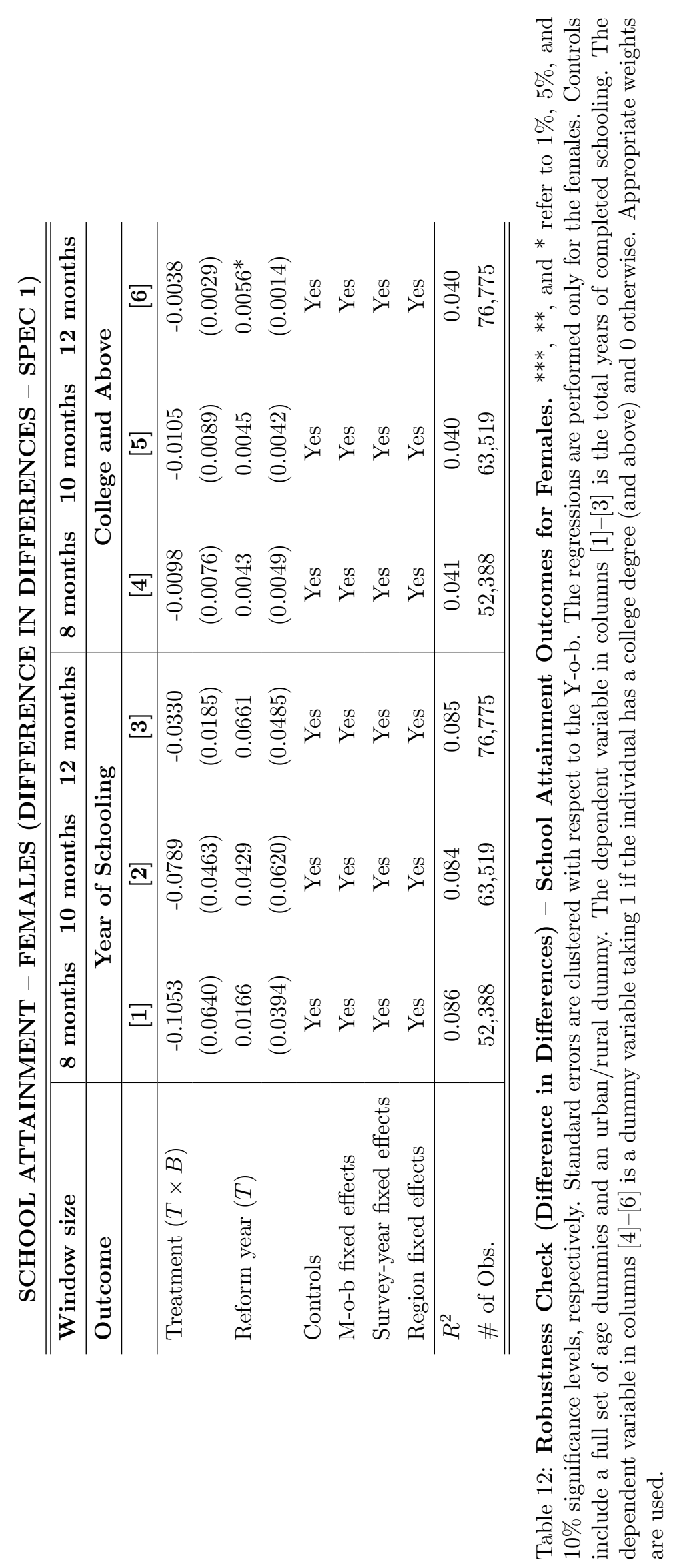




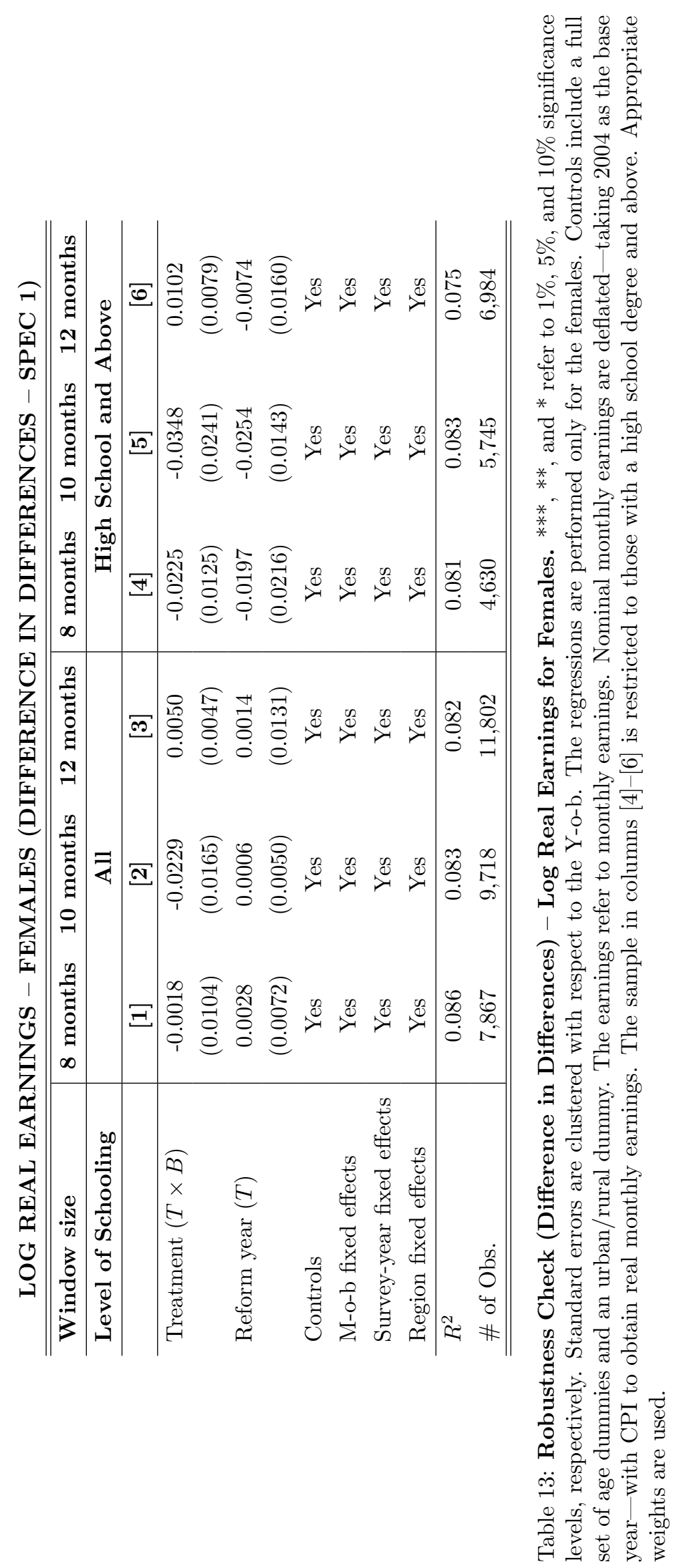




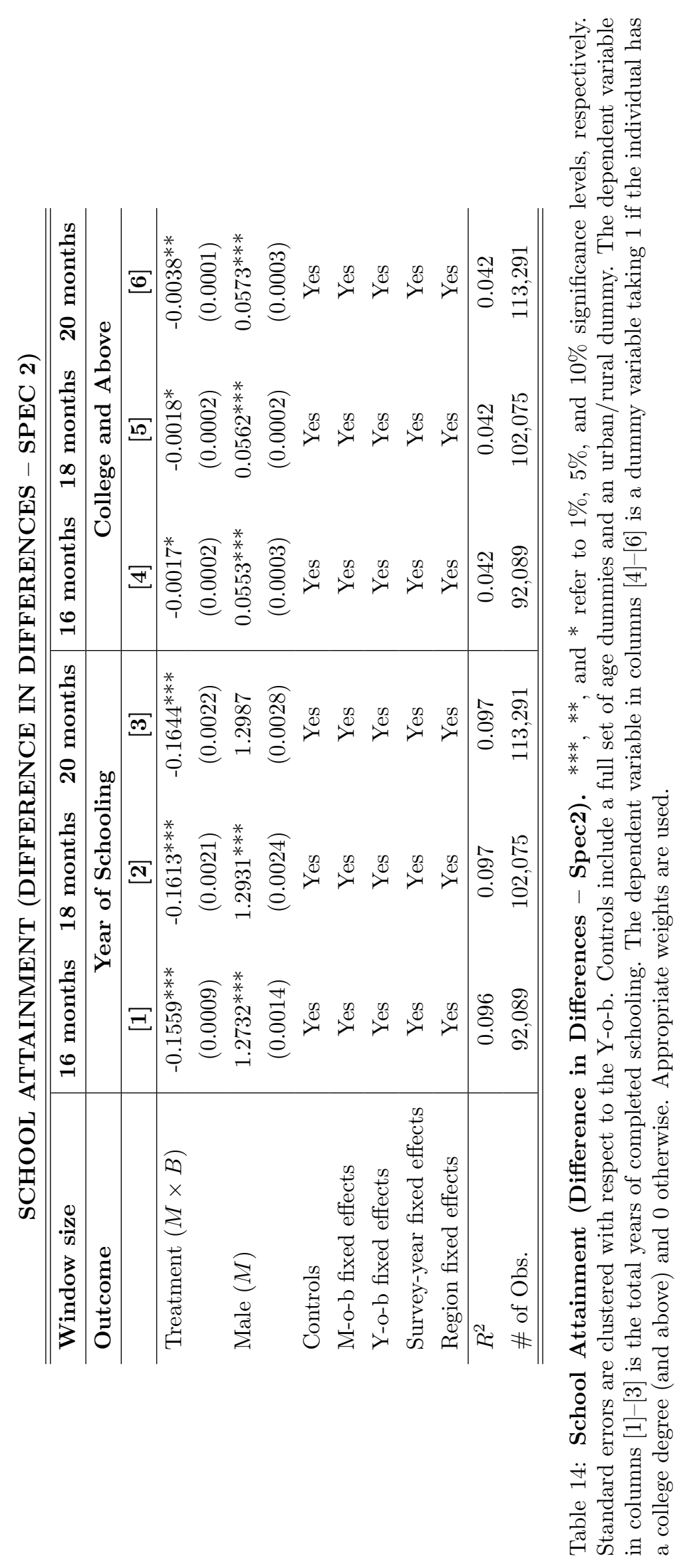




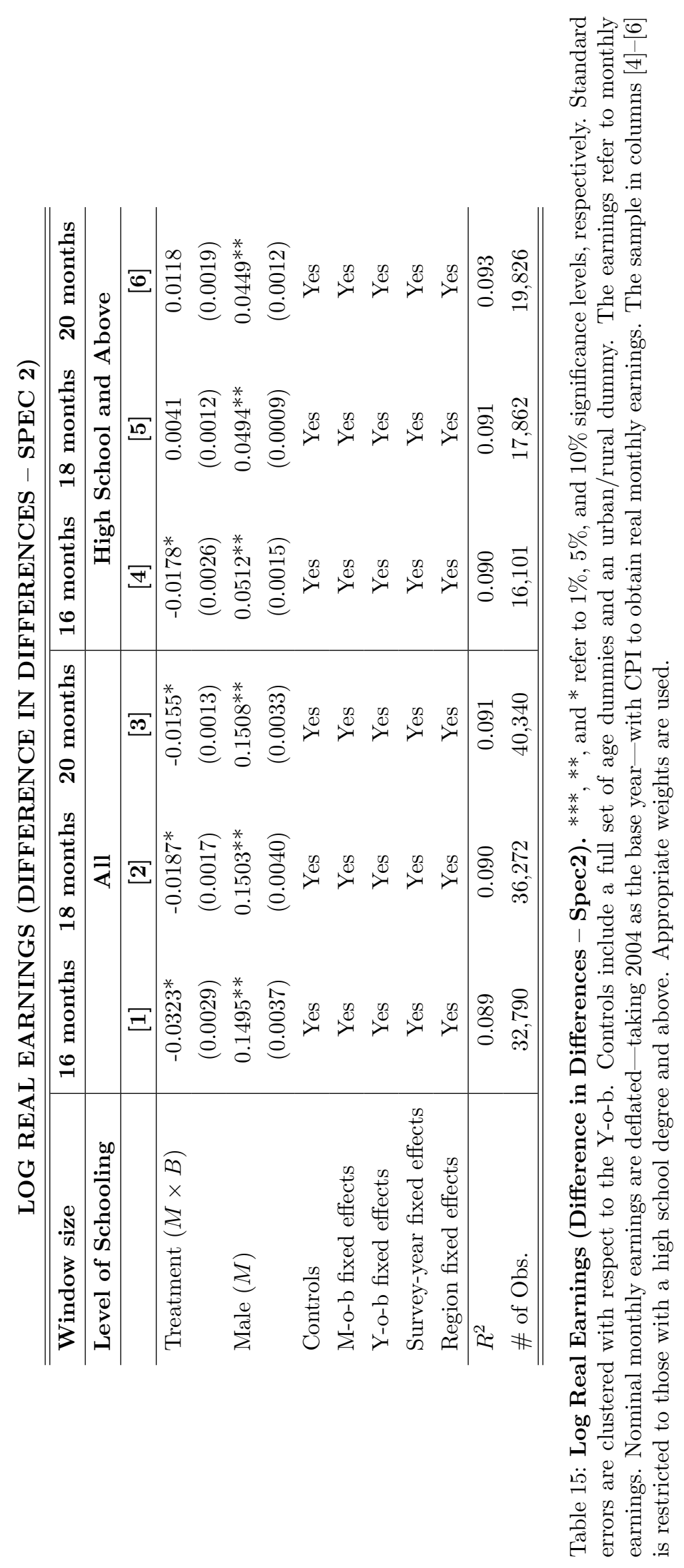




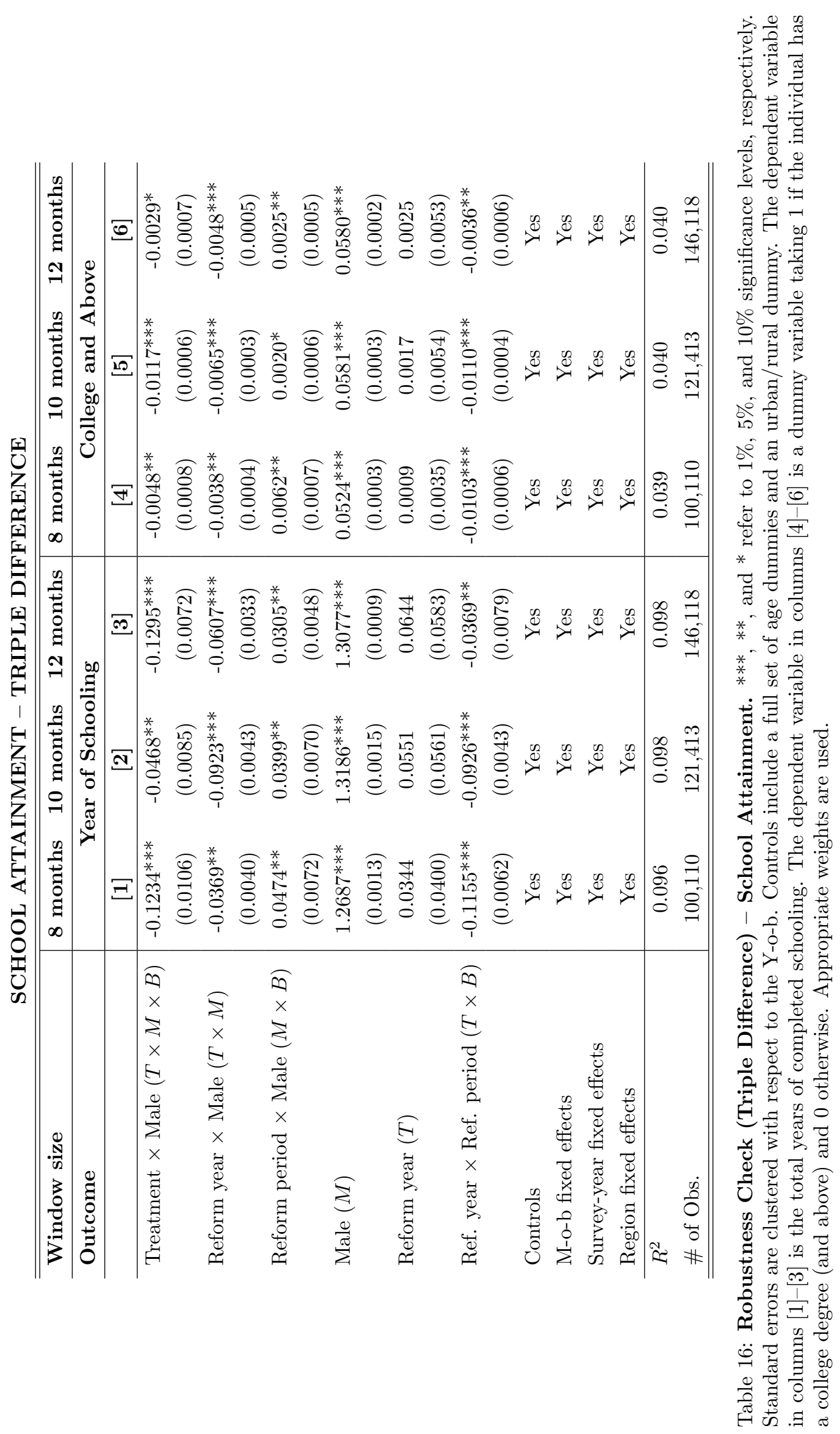




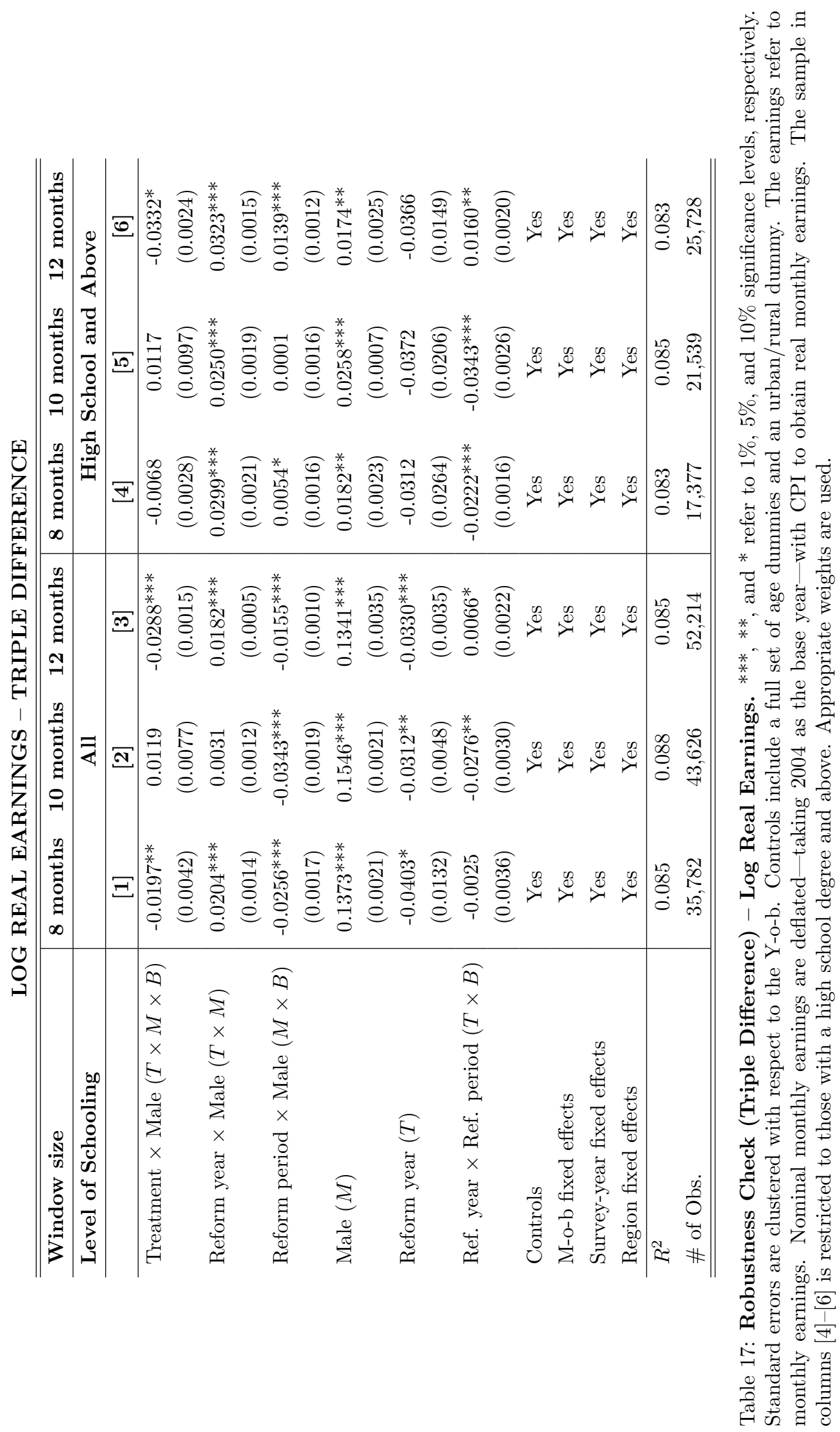




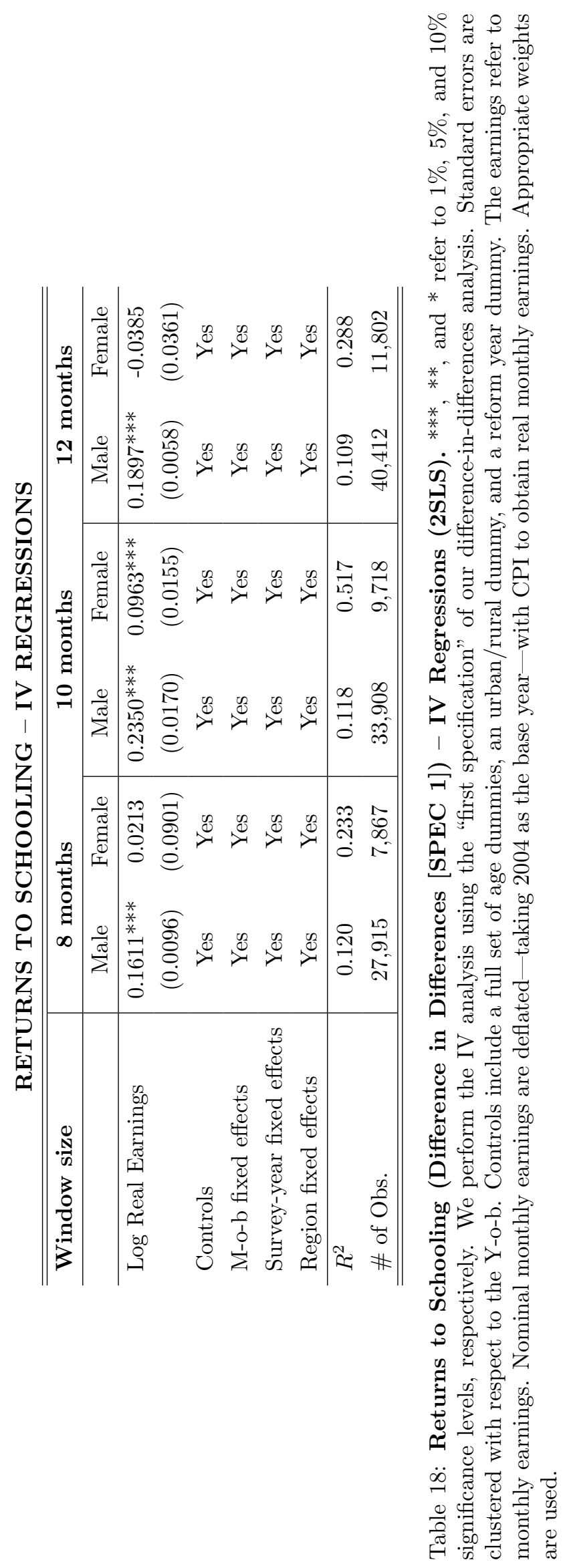

